\title{
UCRL-JRNL-225105
}

LAW RENCE LIVERMORE N A T IO N A L LABORATORY
Ultrafast Structural Rearrangements in the MLCT Excited State for Copper(I) bis-Phenanthrolines in Solution

G. B. Shaw, C. D. Grant, H. Shirota, E. W. Castner J., G. J. Meyer, L. X. Chen

October 9, 2006

Journal of the American Chemical Society 
This document was prepared as an account of work sponsored by an agency of the United States Government. Neither the United States Government nor the University of California nor any of their employees, makes any warranty, express or implied, or assumes any legal liability or responsibility for the accuracy, completeness, or usefulness of any information, apparatus, product, or process disclosed, or represents that its use would not infringe privately owned rights. Reference herein to any specific commercial product, process, or service by trade name, trademark, manufacturer, or otherwise, does not necessarily constitute or imply its endorsement, recommendation, or favoring by the United States Government or the University of California. The views and opinions of authors expressed herein do not necessarily state or reflect those of the United States Government or the University of California, and shall not be used for advertising or product endorsement purposes. 


\title{
Ultrafast Structural Rearrangements
}

\author{
in the MLCT Excited State for
}

\section{Copper(I) bis-Phenanthrolines in Solution}

\author{
George B. Shaw, ${ }^{a+,}$ Christian D. Grant, ${ }^{b+}$ Hideaki Shirota, ${ }^{b}$ Edward W. Castner Jr., ${ }^{b *}$
} Gerald J. Meyer, ${ }^{c}$ Lin X. Chen ${ }^{a} *$

${ }^{a}$ Chemistry Division, Argonne National Laboratory, Argonne, Illinois 60439
${ }^{b}$ Department of Chemistry and Chemical Biology, Rutgers, The State University of New Jersey, Piscataway, New Jersey 08854

${ }^{c}$ Chemistry Department, Johns Hopkins University, Baltimore, Maryland 21218

Email address: 1chen@anl.gov

${ }^{\dagger}$ Current address: NASA Goddard Space Flight Center, Greenbelt, MD 20771

$\$$ Current address Chemistry and Chemical Engineering Division, Lawrence Livermore National Laboratory, Livermore CA 94550 


\section{Abstract}

Ultrafast excited state structural dynamics of $\left[\mathrm{Cu}^{\mathrm{I}}(\mathrm{dmp})_{2}\right]^{+}(\mathrm{dmp}=2,9$-dimethyl-1,10-phenanthroline) have been studied to identify structural origins of transient spectroscopic changes during the photoinduced metal-to-ligand-charge-transfer (MLCT) transition that induces an electronic configuration change from $\mathrm{Cu}(\mathrm{I})\left(3 d^{10}\right)$ to $\mathrm{Cu}(\mathrm{II})\left(3 d^{9}\right)$. This study has important connections with the flattening of the Franck-Condon state tetrahedral geometry and the ligation of $\mathrm{Cu}(\mathrm{II})^{*}$ with the solvent observed in the thermally equilibrated MLCT state by our previous laser-initiated time-resolved x-ray absorption spectroscopy (LITR-XAS) results. To better understand the structural photodynamics of $\mathrm{Cu}(\mathrm{I})$ complexes, we have studied both $\left[\mathrm{Cu}^{\mathrm{I}}(\mathrm{dmp})_{2}\right]^{+}$and $\left[\mathrm{Cu}^{\mathrm{I}}(\mathrm{dpp})_{2}\right]^{+}(\mathrm{dpp}=2,9-$ diphenyl-1,10phenanthroline) in solvents with different dielectric constants, viscosities and thermal diffusivities by transient absorption spectroscopy. The observed spectral dynamics suggest that a solvent-independent inner-sphere relaxation process is occurring despite the large amplitude motions due to the flattening of the tetrahedral coordinated geometry. The singlet fluorescence dynamics of photoexcited $\left[\mathrm{Cu}^{\mathrm{I}}(\mathrm{dmp})_{2}\right]^{+}$ were measured in the coordinating solvent acetonitrile, using the fluorescence upconversion method at different emission wavelengths. At the bluest emission wavelengths, a prompt fluorescence lifetime of $66 \mathrm{fs}$ is attributed to the excited state deactivation processes due to the internal conversion and intersystem crossing at the Franck-Condon state geometry. The differentiation between the prompt fluorescence lifetime with the tetrahedral Franck-Condon geometry and that with the flattened tetrahedral geometry uncovers an unexpected ultrafast flattening process in the MLCT state of $\left[\mathrm{Cu}^{\mathrm{I}}(\mathrm{dmp})_{2}\right]^{+}$. These results provide guidance for future $\mathrm{x}$-ray structural studies on ultrafast time scale, as well as for synthesis towards its applications in solar energy conversion. 


\section{Introduction}

Copper(I) diimine coordination complexes (denoted $\left[\mathrm{Cu}^{\mathrm{I}}(\mathrm{NN})_{2}\right]^{+}$) have a long, rich history that parallels that of their transition-metal cousins, polypyridyl ruthenium(II) systems ${ }^{1-11}$. Current interest is driven by a desire to employ transition metal coordination complexes in applications from solar energy conversion $^{12}$ to chemical sensing ${ }^{13,14}$ and molecular devices. ${ }^{15-17}$ To make these applications economical and viable, much attention is being focused on first row transition metal based systems. In particular, cuprous diimine complexes have been considered as potential substitutes for ruthenium(II) and osmium(II) systems. ${ }^{18}$

McMillin and coworkers ${ }^{3,19-24}$ performed pioneering work for elucidating the unique photophysics and photochemistry of $\left[\mathrm{Cu}^{\mathrm{I}}(\mathrm{NN})_{2}\right]^{+}$complexes and developed a fundamental picture of the photophysics occurring on the nanosecond timescale. ${ }^{6}$ Their experimental observations led to remarkable insights into the properties of these systems in their excited states. McMillin recognized the potential for JahnTeller distortion causing a structural rearrangement from the tetrahedral ground state to square planar or trigonal bipyramidal geometries following a metal-to-ligand-charge-transfer (MLCT) excitation in $\left[\mathrm{Cu}^{\mathrm{I}}(\mathrm{NN})_{2}\right]^{+}$complexes. ${ }^{3,23-25}$ Also, he proposed the model for exciplex quenching by Lewis bases to explain solvent-dependent luminescence and excited state lifetimes. ${ }^{3,19,26}$ Despite the lack of any direct structural evidence, the exciplex formation hypothesis was supported by the correlation between accessibility of the cuprous center by the solvent and the luminescence lifetime, and was widely accepted. ${ }^{3,}$ 19, 27-29 Recent contributions from our laboratory using laser-initiated time-resolved x-ray absorption spectroscopy (LITR-XAS) have confirmed the presence of additional coordination to the copper center by a solvent molecule (or counter ion) for photoexcited $\left[\mathrm{Cu}^{\mathrm{I}}(\mathrm{dmp})_{2}\right]^{+}$in both noncoordinating toluene ${ }^{30}$ and strongly coordinating acetonitrile. ${ }^{31}$ The interaction strength with the solvent molecule is much weaker in the former and stronger in the latter and is supported by the differentiation of the average copper to ligand distance in the thermally equilibrated ${ }^{3}$ MLCT state. 
Recently, there appears to be a renewed awareness of the complicated ultrafast photophysics in $\left[\mathrm{Cu}^{\mathrm{I}}(\mathrm{NN})_{2}\right]^{+}$molecules and their derivatives, as evidenced by the variety of articles that have appeared in the recent literature. ${ }^{18,32-34}$ In our previous contribution, ${ }^{31}$ we combined ultrafast optical transient absorption (TA), time-dependent density functional theory (TD-DFT) and LITR-XAS to gain further insight into the dynamics and structures of the photoexcited $\left[\mathrm{Cu}^{\mathrm{I}}(\mathrm{dmp})_{2}\right]^{+}$MLCT states in a strong Lewis base solvent, acetonitrile. The LITR-XAS measurements with 100-ps time resolution provided compelling evidence for the solute-solvent complexes at the thermally equilibrated MLCT states. The TD-DFT calculations indicated a structural dependence manifested by the dihedral angle between the two dmp ligand planes on the transition energy gap between the ${ }^{3}$ MLCT state and higher excited states, implying that a blue shift of the transient absorption band should appear when the tetrahedral coordination of the Franck-Condon (F-C) state flattens. ${ }^{31,35}$ Such a blue shift was indeed revealed in acetonitrile by our previous TA spectra in the form of spectral narrowing on the red edge of the absorption band occurring on a 10-20 ps timescale following an initial sub-ps rise of a broad excited state absorption band. ${ }^{31}$ It was assumed that intersystem crossing (ISC) from the $\mathrm{F}-\mathrm{C}{ }^{1} \mathrm{MLCT}$ state to the ${ }^{3}$ MLCT manifold occurred on a sub-ps timescale in accord with that observed in $\left[\mathrm{Ru}^{\mathrm{II}}(\mathrm{bpy})_{3}\right]^{2+36}$ Without direct structural measurements with a better time resolution than $100 \mathrm{ps}$, we tentatively attributed the blue shift and its associated 10-20 ps time constant as a signature of the "flattening" distortion of the phenanthroline moieties based on the TD-DFT results and on the timescales for internal rotations of groups with similar sizes in twisted internal charge transfer (TICT) states. ${ }^{37}$

A much slower ISC process has been proposed by Siddique et al. ${ }^{34}$ based on their time-correlated single photon counting (TCSPC) fluorescence lifetime measurements, which revealed a 13-ps fluorescence lifetime. Their spectral assignments were supported by TD-DFT calculations, revealing that the weakened spin-orbital coupling resulting from the structural distortion from tetrahedral geometry, the "flattening", was attributed to the origin of a remarkably slow ISC process. ${ }^{34}$ In the current work, we report both ultrafast transient absorption experiments on $\left[\mathrm{Cu}^{\mathrm{I}}(\mathrm{dmp})_{2}\right]^{+}$in various solvents (acetonitrile, ethylene glycol and toluene), as well as femtosecond fluorescence upconversion 
experiments of $\left[\mathrm{Cu}^{\mathrm{I}}(\mathrm{dmp})_{2}\right]^{+}$in acetonitrile. To our knowledge, this is the second transition metal coordination complex studied by the fluorescence upconversion technique, ${ }^{36}$ applied to this complex independently by ourselves and by Iwamura, Takehashi, and Tahara. ${ }^{\mathrm{i}} \quad$ Because the fluorescence observed in the upconversion experiments most commonly originates from the lowest excited singlet state $\left(\mathrm{S}_{1}\right)$, this technique reveals the temporal signatures of the evolution of the $\mathrm{S}_{1}$ state and thus should define the timescale of $I S C$ with more than a factor of 100 enhancement in time resolution compared to TCSPC measurements. Hence, we hope to infer information about the timescale of the flattening distortion of the phenanthroline ligands from these measurements and correlate the structures of the excited states with their photophysical behaviors, in particular, their structure dependent non-radiative decay processes.

The chemical structures of the complexes and the possible excited state reaction pathways are depicted in Chart 1. The $\left[\mathrm{Cu}^{\mathrm{I}}(\mathrm{dmp})_{2}\right]^{+}$and $\left[\mathrm{Cu}^{\mathrm{I}}(\mathrm{dpp})_{2}\right]^{+}$were selected for this study because they undergo similar photoinduced flattening distortions of the phenanthroline ligands, but differ in their ability to coordinate a fifth ligand and form exciplexes. The phenyl rings of the dpp ligands appear to protect the copper center from Lewis bases much more effectively than the methyl groups of dmp. For example, $\left[\mathrm{Cu}^{\mathrm{I}}(\mathrm{dpp})_{2}\right]^{+}$has long-lived photoluminescent excited states in coordinating solvents, like acetonitrile and methanol, conditions where the $\left[\mathrm{Cu}^{\mathrm{I}}(\mathrm{dmp})_{2}\right]^{+*}$ is completely non-emissive. In addition, x-ray crystallography studies have shown that the oxidized forms of $\left[\mathrm{Cu}^{\mathrm{I}}(\mathrm{dmp})_{2}\right]^{+}$are 5-coordinate with a fifth ligand derived from the solvent or counterion. ${ }^{38,39}$ In contrast, $\left[\mathrm{Cu}{ }^{\mathrm{II}}(\mathrm{dpp})_{2}\right]^{2+}$ is 4-coordinate in the solid state for both the $\mathrm{Cu}(\mathrm{I})$ and $\mathrm{Cu}(\mathrm{II})$ formal oxidation states and there is good evidence that these geometries are maintained in fluid solution. ${ }^{40}$ Therefore, we do not anticipate that the "MLCT-Solvent Complex", shown on the right hand side of Chart 1B, represents a significant relaxation pathway for $\left[\mathrm{Cu}^{\mathrm{I}}(\mathrm{dpp})_{2}\right]^{+*}$, where it is the preferred pathway for $\left[\mathrm{Cu}^{\mathrm{I}}(\mathrm{dmp})_{2}\right]^{+*}$. It was of interest to contrast ultrafast photophysical properties of these similar but clearly unique compounds. Such knowledge will provide

\footnotetext{
${ }^{\text {a }}$ Private communication to EWC.
} 
guidance in synthesizing $\mathrm{Cu}(\mathrm{I})$ complexes with targeted structural constraints in order to achieve desirable excited state properties for solar energy conversion.

\section{Experimental Methods}

\section{Samples}

The $\left[\mathrm{Cu}^{\mathrm{I}}(\mathrm{dmp})_{2}\right]\left(\mathrm{PF}_{6}\right)$ and $\left[\mathrm{Cu}^{\mathrm{I}}(\mathrm{dpp})_{2}\right]\left(\mathrm{PF}_{6}\right)$ were synthesized according to previously published procedures. ${ }^{1,41}$ The acetonitrile, toluene, and ethylene glycol were from Aldrich. The first two solvents were distilled before use. The $\left[\mathrm{Cu}^{\mathrm{I}}(\mathrm{dmp})_{2}\right]\left(\mathrm{PF}_{6}\right)$ was metathesized in the presence of sodium tetrakis(3,5-bis(trifluoromethylphenyl))borate (Boulder Scientific) with a 1:1 ratio in toluene. The concentration used for the transient optical absorption sample was about $0.4 \mathrm{mM}$ and used without degassing.

\section{Transient absorption spectroscopy}

Transient absorption measurements were performed with an apparatus based on an amplified Ti:sapphire laser system as described elsewhere. ${ }^{42}$ The $417 \mathrm{~nm}$ excitation pulses were obtained from the second harmonic of the output from the Ti:Sapphire amplifier. White light continuum probe pulses were generated by focusing a few $\mu \mathrm{J}$ of the Ti:sapphire amplifier output onto a sapphire disc. The white light was split into two beams that served as the reference and the probe respectively. The probe beam and the pump beam were focused to a $0.3 \mathrm{~mm}$ diameter spot at the sample in a nearly collinear geometry, and with a "magic angle" of $54.7^{\circ}$ in relative polarization directions. For the transient absorption anisotropy measurements, the polarization of the white light probe was kept in the horizontal direction (parallel to the laser table) and that of the $417 \mathrm{~nm}$ pump rotated to parallel or perpendicular respected to the probe polarization direction. The pump intensity at each polarization direction was measured and adjusted to be the same with the half wave plate before the polarizer that defined the pump polarization. The sample cuvette path length was $2 \mathrm{~mm}$. The widths of the pump and probe pulses were about $100 \mathrm{fs}$, and the total instrumental response for the pump-probe experiments was about $180 \mathrm{fs}$. The transient absorption changes for a particular probe wavelength as a function of time were 
analyzed by fitting the data with a multi-exponential kinetic model convoluted with a Gaussian instrument response function with 180 fs FWHM. In all cases the samples were excited at $417 \mathrm{~nm}$.

\section{Fluorescence upconversion spectroscopy}

The fluorescence upconversion system has been described previously. ${ }^{43-46}$ Briefly, the fundamental beam, centered at $837 \mathrm{~nm}$, of a Spectra Physics Tsunami femtosecond Ti:sapphire laser was focused into a type I BBO nonlinear crystal with 1-mm path length, generating $418.5 \mathrm{~nm}$ light with an average power of $\sim 75 \mathrm{~mW}$. The $418.5 \mathrm{~nm}$ light was then used to excite the $\left[\mathrm{Cu}^{\mathrm{I}}(\mathrm{dmp})_{2}\right]^{+}$sample dissolved in anhydrous acetonitrile with the remaining fundamental used as the gate for the upconverted emission using phase matched sum frequency generation. The sum frequency was generated in a type I BBO nonlinear crystal with $0.4 \mathrm{~mm}$ path length. The polarization was set to the magic angle $\left(54.7^{\circ}\right)$ between the excitation and probe beams thereby removing any reorientational dynamics from the fluorescence transient. The upconverted signal was passed through a monochromator (Acton SP-150) for wavelength selection followed by detection with a photomultiplier, pre-amplifier, and photon counter (Stanford SR400). The instrument temporal response was measured by the cross correlation between the second harmonic and the fundamental (third harmonic generation-THG) and had a full-width at half-maximum of $\sim 180$ fs. The $\left[\mathrm{Cu}^{\mathrm{I}}(\mathrm{dmp})_{2}\right]^{+}$sample was flowed rapidly through a 1-mm path length cuvette to avoid thermal lensing. The sample OD was $\sim 1$ for the $1 \mathrm{~mm}$ path length. Upconverted transients were measured for 550,600 , and $630 \mathrm{~nm}$. Because of the very low fluorescence intensity, typically 20 scans were collected and then summed. All fluorescence transients were fit to a sum of exponentials convolved with the measured THG instrument response function.

\section{Results}

\section{The ground state absorption spectra}

The ground state electronic absorption spectra for $\left[\mathrm{Cu}^{\mathrm{I}}(\mathrm{dmp})_{2}\right]^{+}$and $\left[\mathrm{Cu}^{\mathrm{I}}(\mathrm{dpp})_{2}\right]^{+}$in acetonitrile are shown in Figure 1 with maxima at 456 and $441 \mathrm{~nm}$, respectively. These bands correspond to MLCT transitions for each complex. ${ }^{21,22}$ The spectra in ethylene glycol and toluene showed no differences in 
peak shape or position and are thus not displayed. These spectra are in agreement with those in the literature. $^{2,22,28}$

\section{The excited state transient absorption spectra}

Transient absorption spectra were collected from very early times $(<500 \mathrm{fs})$ through 2 ns after photoexcitation for $\left[\mathrm{Cu}^{\mathrm{I}}(\mathrm{dmp})_{2}\right]^{+}$in the three solvents and for $\left[\mathrm{Cu}^{\mathrm{I}}(\mathrm{dpp})_{2}\right]^{+}$in acetonitrile. For $\left[\mathrm{Cu}^{\mathrm{I}}(\mathrm{dmp})_{2}\right]^{+}$, single wavelength transients were measured at seven probe wavelengths $(475,500,520$, $540,560,580$ and $600 \mathrm{~nm}$ ) to obtain the kinetics in every region of the transient spectrum. Each of the transients was fit to a sum of exponentials that was convolved with a Gaussian of FWHM of 180 fs to approximate the instrument response function for the cross-correlation between the pump and probe pulses at a given probe wavelength. The results of the nonlinear least square fitting are displayed in Tables 1-3. For $\left[\mathrm{Cu}^{\mathrm{I}}(\mathrm{dpp})_{2}\right]^{+}$in acetonitrile, single wavelength transient kinetics were also measured throughout the differential absorption spectrum $(545,565,585,605,625$ and $645 \mathrm{~nm})$. The exponential time constants obtained from fitting the transients are reported in Table 4.

Table 1. Time constants from nonlinear least squares fitting of transient kinetics at various wavelengths for $\left[\mathrm{Cu}(\mathrm{dmp})_{2}\right]^{+}$in acetonitrile.

time

component

$475 \mathrm{~nm}$

$500 \mathrm{~nm}$

$520 \mathrm{~nm}$

$540 \mathrm{~nm}^{\mathrm{c}} \quad 560 \mathrm{~nm}$

$580 \mathrm{~nm}$

$600 \mathrm{~nm}$

(ps)

\begin{tabular}{cccccccc}
\hline fast $^{\mathrm{a}}$ & $\tau_{\mathrm{D} 1}=0.48$ & $\tau_{\mathrm{D} 1}=0.58$ & $\tau_{\mathrm{D} 1}=0.50$ & $\tau_{\mathrm{D} 1}=0.44$ & $\tau_{\mathrm{R} 1}=0.41$ & $\tau_{\mathrm{R} 1}=0.55$ & $\tau_{\mathrm{R} 1}=0.78$ \\
intermediate $^{\mathrm{a}}$ & $\tau_{\mathrm{R} 1}=12$ & $\tau_{\mathrm{R} 1}=12$ & $\tau_{\mathrm{R} 1}=12$ & - & $\tau_{\mathrm{R} 2}=10$ & $\tau_{\mathrm{D} 1}=11$ & $\tau_{\mathrm{D} 1}=10$ \\
long $^{\text {a,b }}$ & $\tau_{\mathrm{R} 2}=1600$ & $\tau_{\mathrm{D} 2}=1600$ & $\tau_{\mathrm{D} 2}=1600$ & $\tau_{\mathrm{D} 2}=1670$ & $\tau_{\mathrm{D} 1}=1640$ & $\tau_{\mathrm{D} 2}=1550$ & $\tau_{\mathrm{D} 2}=1510$
\end{tabular}

\footnotetext{
${ }^{\mathrm{a}}$ the subscripts $\mathrm{R}$ and $\mathrm{D}$ (rise and decay) indicate the direction of the transient signal for the given timescale $(\tau)$.

${ }^{b}$ this timescale reflects the excited state lifetime in acetonitrile.

${ }^{c}$ after the initial fast rise of the absorption, the $540 \mathrm{~nm}$ transient exhibited only the slow decay of the excited state lifetime.
} 
Table 2. Time constants from nonlinear least squares fitting of transient kinetics at various wavelengths for $\left[\mathrm{Cu}(\mathrm{dmp})_{2}\right]^{+}$in ethylene glycol.

time

component $475 \mathrm{~nm} \quad 500 \mathrm{~nm}$

$520 \mathrm{~nm}$

$540 \mathrm{~nm}$

$560 \mathrm{~nm}$

$580 \mathrm{~nm}$

$600 \mathrm{~nm}$

(ps)

\begin{tabular}{cccccccc}
\hline fast $^{\mathrm{a}}$ & $\tau_{\mathrm{D} 1}=0.41$ & $\tau_{\mathrm{R} 1}=0.31$ & $\tau_{\mathrm{R} 1}=0.34$ & $\tau_{\mathrm{R} 1}=0.62$ & $\tau_{\mathrm{R} 1}=0.40$ & $\tau_{\mathrm{R} 1}=0.24$ & $\tau_{\mathrm{R} 1}=0.55$ \\
intermediate $^{\mathrm{a}}$ & $\tau_{\mathrm{R} 1}=4.0$ & $\tau_{\mathrm{R} 2}=8.4$ & $\tau_{\mathrm{R} 2}=15$ & $\tau_{\mathrm{R} 2}=14$ & $\tau_{\mathrm{R} 2}=16$ & $\tau_{\mathrm{D} 1}=15$ & $\tau_{\mathrm{D} 1}=9.3$ \\
long $^{\mathrm{a}, \mathrm{b}}$ & $\tau_{\mathrm{R} 2}=1375$ & $\tau_{\mathrm{D} 1}=1300$ & $\tau_{\mathrm{D} 1}=1300$ & $\tau_{\mathrm{D} 1}=1210$ & $\tau_{\mathrm{D} 1}=1200$ & $\tau_{\mathrm{D} 2}=1350$ & $\tau_{\mathrm{D} 2}=1100$
\end{tabular}

${ }^{\mathrm{a}}$ the subscripts $\mathrm{R}$ and $\mathrm{D}$ (rise and decay) indicate the direction of the transient signal for the given timescale $(\tau)$

${ }^{\mathrm{b}}$ this timescale reflects the excited state lifetime in ethylene glycol.

Table 3. Time constants from nonlinear least squares fitting of transient kinetics at various wavelengths for $\left[\mathrm{Cu}(\mathrm{dmp})_{2}\right]^{+}$in toluene.

time

$\begin{array}{llllllll}\text { component } & 475 \mathrm{~nm} & 500 \mathrm{~nm} & 520 \mathrm{~nm} & 540 \mathrm{~nm}^{\mathrm{c}} \quad 560 \mathrm{~nm} \quad 580 \mathrm{~nm} \quad 600 \mathrm{~nm}\end{array}$

$(\mathrm{ps})^{\mathrm{a}}$

$\begin{array}{llllllll}\text { fast }^{\mathrm{b}} & \tau_{\mathrm{D} 1}=0.21 & \tau_{\mathrm{R} 1}=0.30 & \tau_{\mathrm{R} 1}=0.24 & \tau_{\mathrm{R} 1}=0.36 & \tau_{\mathrm{R} 1}=0.35 & \tau_{\mathrm{R} 1}=0.76 & \tau_{\mathrm{R} 1}=0.68\end{array}$

intermediate $^{\mathrm{b}} \quad \tau_{\mathrm{R} 1}=2.9 \quad \tau_{\mathrm{R} 2}=33 \quad \tau_{\mathrm{R} 2}=22 \quad-\quad \tau_{\mathrm{R} 2}=13 \quad \tau_{\mathrm{D} 1}=10 \quad \tau_{\mathrm{D} 1}=10$

${ }^{\mathrm{a}}$ the long time constants are not reported because the excited state lifetime of $\mathrm{Cu}[\mathrm{dmp}]_{2}{ }^{+}$in toluene ( $\sim 98 \mathrm{~ns}$ ) exceeds our experimental limits, and has been measured in our previous studies. ${ }^{30,62}$

${ }^{\mathrm{b}}$ the subscripts $\mathrm{R}$ and $\mathrm{D}$ (rise and decay) indicate the direction of the transient signal for the given timescale $(\tau)$.

${ }^{c}$ after the initial fast rise of the absorption, the $540 \mathrm{~nm}$ transient exhibited only the slow decay of the excited state lifetime.

Table 4. Time constants from nonlinear least squares fitting of transient kinetics at various wavelengths for $\left[\mathrm{Cu}(\mathrm{dpp})_{2}\right]^{+}$in acetonitrile.

time

componen

$(\mathrm{ps})^{\mathrm{a}}$

$545^{\mathrm{c}} \mathrm{nm}$

$565 \mathrm{~nm}$

$585 \mathrm{~nm}$

$605 \mathrm{~nm}$

$625 \mathrm{~nm}$

$645 \mathrm{~nm}$

$$
\text { fast }^{b}
$$

$\tau_{\mathrm{D} 1}=2.5$

$\tau_{\mathrm{D} 1}=0.78$

$\tau_{\mathrm{D} 1}=0.60$

$\tau_{\mathrm{R} 1}=0.27$

$\tau_{\mathrm{R} 1}=0.39$

$\tau_{\mathrm{R} 1}=0.94$

intermediate $^{b}$

$\tau_{\mathrm{D} 2}=9.0$

$\tau_{\mathrm{R} 1}=10$

$\tau_{\mathrm{D} 1}=11$

$\tau_{\mathrm{D} 1}=11$

$\tau_{\mathrm{D} 1}=9.7$

\footnotetext{
${ }^{\mathrm{a}}$ the long time constant is not reported because the excited state lifetime of $\mathrm{Cu}[\mathrm{dpp}]_{2}{ }^{+}$in acetonitrile ( $110 \mathrm{~ns}$ ) exceeds our experimental limits
} 
${ }^{\mathrm{b}}$ the subscripts $\mathrm{R}$ and $\mathrm{D}$ (rise and decay) indicate the direction of the transient signal for the given timescale $(\tau)$

${ }^{c}$ after an early decay of the absorption, the 545 transient exhibited only the slow decay of the excited state lifetime

\section{Transient absorption spectra of $\left[\mathrm{Cu}^{\mathrm{I}}(\mathrm{dmp})_{2}\right]^{+}$Transient absorption spectra were measured in the} spectral region of $450-775 \mathrm{~nm}$. In the acetonitrile solution, the entire transient spectrum exhibits a rise without any distinct features. In the ethylene glycol, the absorption band arises from the blue side, and then quickly grows in toward the red $(568 \mathrm{~nm})$. In toluene, the initial absorption arises from the red side and quickly grows in toward the blue $(568 \mathrm{~nm})$. Although these subtle differences are observed in the shape and direction of sub-ps spectral evolution among the three solutions within 1 ps of the excitation, their significance will be discussed in later sections.

On the other hand, the consistency of the transient spectra at $\sim 1.2 \mathrm{ps}$ in the three different solvents is noteworthy. Beyond this point, the similarity of the spectral evolution that takes place during the first $20 \mathrm{ps}$ for $\left[\mathrm{Cu}^{\mathrm{I}}(\mathrm{dmp})_{2}\right]^{+}$in these very different solvents is remarkable. The uniformity of the time it takes for the broad featureless spectrum to shift to the blue, narrow, and develop the dual peak structure seems to imply that the dynamical process(es) associated with this evolution is apparently unrelated to the solvent properties within the first 20 ps of the photoexcitation, which is an unexpected observation for dynamics occurring on this timescale. The origin of this spectral evolution and its associated timescale are addressed in detail in the Discussion section.

\section{Transient absorption kinetics of $\left[\mathrm{Cu}^{\mathrm{I}}(\mathrm{dmp})_{2}\right]^{+}$Kinetics traces were collected at seven wavelengths} across the transient spectrum $(475,500,520,540,560,580$ and $600 \mathrm{~nm})$. These measurements sampled every region of the excited state absorption band as well as the ground state bleaching $(<500 \mathrm{~nm})$. The results of nonlinear least squares analysis of the data at each probe wavelength for acetonitrile, ethylene glycol and toluene solutions are presented in Tables $1-3$, respectively. Monitoring the probe wavelengths on the red side of the absorption band (i.e. the 580 and $600 \mathrm{~nm}$ transients) provides the 
timescale of the spectral evolution from the initial broad spectrum to the narrowed, blue-shifted transient spectrum previously observed for the long-lived ${ }^{3} \mathrm{MLCT}$ state of $\left[\mathrm{Cu}^{\mathrm{I}}(\mathrm{dmp})_{2}\right]^{+}$.

Examination of the time constants obtained from the fitting of the kinetics reveals the timescales for the spectral evolution of the excited state absorption band. After the sub-ps rise at $560 \mathrm{~nm}$ (the peak of the long-time transient spectrum), the kinetics trace exhibits a slower, $\sim 10-15$ ps rise. Following the initial sub-ps rise, the decay of spectral intensity at 580 and $600 \mathrm{~nm}$ which results from the blue shift and narrowing of the absorption band also occurs with a time constant of roughly $10-15$ ps, independent of the solvent. The corresponding timescales for the rise of the peak at $560 \mathrm{~nm}$ and the decay of the red side of the absorption band complement one another and clearly result from evolution of the broad, early spectrum to the structured, long-time spectrum. Figure 5, Figure 6 and Figure 7 depict the transient kinetics within the first 40 ps for $\left[\mathrm{Cu}^{\mathrm{I}}(\mathrm{dmp})_{2}\right]^{+}$in the three solvents at 560,580 and $600 \mathrm{~nm}$, respectively. Despite the differences in bulk properties among these solvents (see Discussion section), these results indicate that there is little difference in timescale for spectral evolution among the various solutions within 20 ps after photoexcitation.

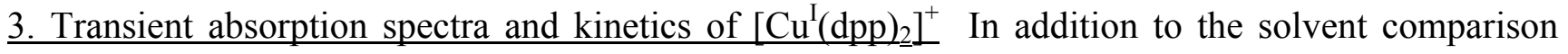
described above, we have also performed experiments on $\left[\mathrm{Cu}(\mathrm{dpp})_{2}\right]^{+}$with two phenyl groups at the 2 and 9 positions. dpp is clearly considerably bulkier than dmp, with the molecular volume ratios for $\left[\mathrm{Cu}^{\mathrm{I}}(\mathrm{dpp})_{2}\right]^{+}$to $\left[\mathrm{Cu}^{\mathrm{I}}(\mathrm{dmp})_{2}\right]^{+}$being $\sim 1.5: 1$. The electronic structure is also somewhat different than that of dmp because the phenyl substituents in $\left[\mathrm{Cu}^{\mathrm{I}}(\mathrm{dpp})_{2}\right]^{+}$help stabilize the photoexcited electron in the MLCT excited state though $\pi$-conjugation whereas the methyl groups in $\left[\mathrm{Cu}^{\mathrm{I}}(\mathrm{dmp})_{2}\right]^{+}$are electrondonating and serve to destabilize the MLCT state. Consequently, the transient absorption spectrum of $\left[\mathrm{Cu}^{\mathrm{I}}(\mathrm{dpp})_{2}\right]^{+}$is located further to the red than for $\left[\mathrm{Cu}^{\mathrm{I}}(\mathrm{dmp})_{2}\right]^{+}$. The transient spectra from $1.2 \mathrm{ps}-2 \mathrm{~ns}$ for $\left[\mathrm{Cu}^{\mathrm{I}}(\mathrm{dpp})_{2}\right]^{+}$in acetonitrile are displayed in Figure 8 and the inset depicts the spectra within the first 1.2 ps. As observed in $\left[\mathrm{Cu}^{\mathrm{I}}(\mathrm{dmp})_{2}\right]^{+}$, a broad, featureless spectrum appears within $\sim 1.2$ ps and evolves to a blue-shifted, narrowed spectrum that possesses a dual peak structure (presumably due to the dpp ${ }^{\circ}$ absorption). Also, like $\left[\mathrm{Cu}^{\mathrm{I}}(\mathrm{dmp})_{2}\right]^{+}$, this spectral evolution is complete within $\sim 20 \mathrm{ps}$. 
Kinetics traces for $\left[\mathrm{Cu}^{\mathrm{I}}(\mathrm{dpp})_{2}\right]^{+}$in acetonitrile were collected at six wavelengths across the transient spectrum $(545,565,585,605,625$ and $645 \mathrm{~nm})$. The results of nonlinear least squares fitting of the kinetics data are found in Table 4. As was the convention for the $\left[\mathrm{Cu}^{\mathrm{I}}(\mathrm{dmp})_{2}\right]^{+}$data, monitoring the probe wavelengths on the red side of the absorption band (i.e. the 605 and $625 \mathrm{~nm}$ transients) provides the timescale of the spectral evolution from the initial broad spectrum to the narrowed, blue-shifted transient spectrum previously observed for the long-lived ${ }^{3} \mathrm{MLCT}$ state of $\left[\mathrm{Cu}^{\mathrm{I}}(\mathrm{dpp})_{2}\right]^{+}$. Following a sub-ps rise of the transient absorption at $585 \mathrm{~nm}$ (the peak of the long-time spectrum) a slower rise of 10 ps is observed. At 605 and $625 \mathrm{~nm}$, after the initial sub-ps rise, a decay of spectral intensity due to blue shifting and narrowing of the excited state absorption band occurs with a time constant of $11 \mathrm{ps}$, and apparently corresponds to the growth at $585 \mathrm{~nm}$.

This $\sim 10$ ps timescale is also consistent with the spectral evolution observed for $\left[\mathrm{Cu}^{\mathrm{I}}(\mathrm{dmp})_{2}\right]^{+}$. If we take into account the slightly different spectral regions for the excited state absorption bands of the two molecules, it should be possible to compare the kinetics involved in the evolution from the initial broad spectra to the narrowed, blue shifted spectra. By choosing a probe wavelength on the red side of the excited state absorption peaks, the excited state absorption kinetics of $\left[\mathrm{Cu}^{\mathrm{I}}(\mathrm{dpp})_{2}\right]^{+}$and $\left[\mathrm{Cu}^{\mathrm{I}}(\mathrm{dmp})_{2}\right]^{+}$can be reasonably compared between the two molecules. Such a comparison is displayed in Figure 9. For $\left[\mathrm{Cu}^{\mathrm{I}}(\mathrm{dmp})_{2}\right]^{+}$in acetonitrile, the probe wavelength is $600 \mathrm{~nm}$ and for $\left[\mathrm{Cu}^{\mathrm{I}}(\mathrm{dpp})_{2}\right]^{+}$in acetonitrile, 635 $\mathrm{nm}$ corresponds to the center of the red edge of the absorption band. Although the kinetics data for $\left[\mathrm{Cu}^{\mathrm{I}}(\mathrm{dpp})_{2}\right]^{+}$at $635 \mathrm{~nm}$ are not shown in Table 4 , the time constants $\left(\tau_{\mathrm{R} 1}=1.1 \mathrm{ps}\right.$ and $\left.\tau_{\mathrm{D} 1}=11 \mathrm{ps}\right)$ are similar to those observed at 625 and $645 \mathrm{~nm}$. Moreover, the timescale for decay resulting from the blue shift in $\left[\mathrm{Cu}^{\mathrm{I}}(\mathrm{dpp})_{2}\right]^{+}$is $11 \mathrm{ps}$ which is nearly identical to the $10 \mathrm{ps}$ timescale for the same evolution observed in $\left[\mathrm{Cu}^{\mathrm{I}}(\mathrm{dmp})_{2}\right]^{+}$.

The sum of these results shows the dynamical evolution within the first $\sim 20$ to $40 \mathrm{ps}$ for $\left[\mathrm{Cu}^{\mathrm{I}}(\mathrm{dmp})_{2}\right]^{+}$ in three different solvents as well as a related molecule, $\left[\mathrm{Cu}^{\mathrm{I}}(\mathrm{dpp})_{2}\right]^{+}$, which possesses bulkier ligands. However, despite the changes in the local environments (i.e. solvent and substituent), there seem to be more similarities than differences as these molecules evolve from the $\mathrm{F}-\mathrm{C}{ }^{1} \mathrm{MLCT}$ state to the thermally 
equilibrated, flattened ${ }^{3} \mathrm{MLCT}$ state. These results were not anticipated and require further elaboration to explain how they arose.

\section{Transient absorption anisotropy of $\left[\mathrm{Cu}^{\mathrm{I}}(\mathrm{dmp})_{2}\right]^{+}$in acetonitrile}

Transient excited state absorption anisotropy $\mathrm{r}(\mathrm{t})$ of $\left[\mathrm{Cu}^{\mathrm{I}}(\mathrm{dmp})_{2}\right]^{+}$in acetonitrile was measured at 560 nm, near the peak of the excited state absorption, shown in Figure 10. The transient absorption anisotropy $r(t)$ as a function of time can be expressed by $r(t)=[A \|(t)-A \perp(t)] /[A \|(t)+2 A \perp(t)]$, where $\mathrm{A} \|, \perp(\mathrm{t})$ are the absorption of the probe light by the sample in the polarization directions parallel and perpendicular respected to the excitation polarization. $r(t)$ can also be expressed by a function of the second order Legendre polynomial $P_{2}(x)=\left(3 x^{2}-1\right) / 2$, as $\mathrm{r}(\mathrm{t})=2 / 5<P_{2}\left[\mu_{a}(0) \cdot \mu_{a}{ }^{\prime}(t)\right]>$, where $\mu_{a}$ and $\mu_{a}$ ' are transition dipole vectors. ${ }^{47}$ At $t=0, r(0)=2 / 5\left(3 \cos ^{2} \lambda-1\right) / 2$, where $\lambda$ is the angle between two vectors along the transition dipole directions induced by the pump and the probe pulses. In our measurements, $\mu_{a}$ is for $\mathrm{S}_{0} \rightarrow \mathrm{S}_{\mathrm{n}}$, and $\mu_{a}$, for $\mathrm{S}_{1} \rightarrow \mathrm{S}_{\mathrm{n}}$ or $\mathrm{T}_{1} \rightarrow \mathrm{T}_{\mathrm{n}}$. The measurement was intended to resolve any fast internal rotational motion due to the structural change at the MLCT state. The initial anisotropy value $\mathrm{r}(0)$ of -0.16 indicates a near orthogonal orientation of the transition dipoles for $\mathrm{S}_{0} \rightarrow \mathrm{S}_{\mathrm{n}}$ transition and $\mathrm{S}_{1} \rightarrow \mathrm{S}_{\mathrm{n}}$ or $\mathrm{T}_{1} \rightarrow \mathrm{T}_{\mathrm{n}}$ transition. Therefore, if the former is a vector from the $\mathrm{Cu}$ center along the $\mathrm{C}_{2}$ axis of dmp ligand as expected for the MLCT transition and confirmed by the TD-DFT calculations, ${ }^{31}$ the latter will be nearly perpendicular from that direction in the ligand plane (Figure 10). The nonlinear least square fit of $\mathrm{r}(\mathrm{t})$ results in a bi-exponential function with two time constants, $31 \mathrm{ps}$ and $0.5 \mathrm{ps}$, corresponding to the overall tumbling of the molecule in solution and the internal rotational depolarization. If the two transition dipoles are nearly perpendicular with each other as suggested by the value of $r(0)$ and illustrated in the Figure 10 inset, the flattening itself will not change the relative orientations between them. Hence the $0.5 \mathrm{ps}$ time constant either involves motions that alter the angle between the two dipoles, such as the rocking motion bending the $\mathrm{C}_{2}$ axis of the molecule, or is due to changes in the absorption cross section of the transitions of the excited state molecule from the F-C state geometry to the flattened geometry and from $\mathrm{S}_{1}$ to $\mathrm{T}_{1}$. Because several ultrafast processes, such as 
internal conversion, intersystem crossing, and flattening of the F-C state geometry, could all take place in such a time scale, it is difficult to determine the exact origin of the fast decay of $r(t)$ (see below).

\section{Ultrafast fluorescence upconversion of $\left[\mathrm{Cu}^{I}(\mathrm{dmp})_{2}\right]^{+}$in acetonitrile}

Figure 11 shows the fluorescence upconversion transients for $\left[\mathrm{Cu}^{\mathrm{I}}(\mathrm{dmp})_{2}\right]^{+}$in acetonitrile solution. Transients were collected at three different wavelengths 550, 600, and $630 \mathrm{~nm}$. According to the steady-state emission measurements, the emission band is peaked at $750 \mathrm{~nm}$ with its blue edge starting from $550 \mathrm{~nm}^{34}$ Therefore, our measurements are on the blue side of the steady-state emission band. The transients were obtained in two different time windows $\sim 2$ ps (shown for $550 \mathrm{~nm}$ data only in Fig. 11A) for all three wavelengths and $12 \mathrm{ps}$ (Fig. 11B) for 600 and $630 \mathrm{~nm}$. Bi-exponential fits to the transients are represented as a solid red line through the data (filled black circles). Reduced residuals are shown for the fits at the top portion of each transient. As can be seen from the reduced residuals in all cases the fits are quite good, but it should be noted that a single exponential cannot adequately fit the data. The instrument response function (the cross correlation between the pump beam and the fundamental) is approximately 180 fs FWHM (instrument response function in Fig 11A top graph 550 nm emission).

Table 5. Time constants from nonlinear least squares fitting of fluorescence upconversion data at various wavelengths for $\left[\mathrm{Cu}(\mathrm{dmp})_{2}\right]^{+}$in acetonitrile.

$$
\begin{array}{llll}
\text { time constant }(\mathrm{fs})^{\mathrm{a}} & 550 \mathrm{~nm} & 600 \mathrm{~nm} & 630 \mathrm{~nm}
\end{array}
$$

$\begin{array}{cccc}\text { fast } & \tau_{\mathrm{f} 1}=66(95 \%) & \tau_{\mathrm{f} 1}=264(66 \%) & \tau_{\mathrm{f} 1}=733(70 \%) \\ \text { intermediate } & \tau_{\mathrm{f} 2}=471(5 \%) & \tau_{\mathrm{f} 2}=1,165(34 \%) & \tau_{\mathrm{f} 2}=10,930(30 \%)\end{array}$

${ }^{\mathrm{a}}$ The number in parenthesis show the normalized fraction for each component.

The salient features of the ultrafast fluorescence transients are as follows. The gated emission intensity is extremely weak having only about 30 counts in the peak channel at $550 \mathrm{~nm}$ and only 10 
counts in the peak channel for the 600 and $630 \mathrm{~nm}$ wavelengths. Thus it was necessary to collect 20 transients and sum them to obtain signal qualities adequate for convolute-and-compare nonlinear least squares multi-exponential analysis. The weak gated fluorescence signal strength agrees with the very weak fluorescence quantum yield of $10^{-5} .^{34}$ The emission transients are bi-exponential decays and are strongly wavelength dependent. The upconversion transients cannot be fit to a rising exponential component for any of the three wavelengths measured. The time components of the fluorescence decays become longer with redder detection wavelengths. The results from the nonlinear fitting are summarized in Table 5. At $550 \mathrm{~nm}$, the time constants derived from the fit to the data were 66 and 470 fs with $\sim 95 \%$ of the decay clearly residing in the 66 -fs time component. The emission at $550 \mathrm{~nm}$ was completely decayed by 2 ps. The 66 -fs component is very similar to another transition metal complex, $\left[\mathrm{Ru}(\mathrm{bpy})_{3}\right]^{+}$, as studied by fluorescence upconversion where a $40-\mathrm{fs}$ emission decay was determined and attributed to ISC from the ${ }^{1} \mathrm{MLCT}$ to the ${ }^{3} \mathrm{MLCT}$. ${ }^{36}$ The fluorescence transient at $600 \mathrm{~nm}$ yielded time constants of $260 \mathrm{fs}$ and $1.2 \mathrm{ps}$ while fits to the $630 \mathrm{~nm}$ emission yielded lifetimes of $730 \mathrm{fs}$ and $11 \mathrm{ps}$. The $630 \mathrm{~nm}$ transient did not completely decay to zero intensity by the end of the $12 \mathrm{ps}$ time window, so the long time constant derived from the nonlinear least square fit for this transient is only approximate. The fast component is the major contributor for the decays at all three emission wavelengths, 550, 600 and $630 \mathrm{~nm}$, but its amplitude is smaller at redder detected wavelengths than at bluer. At 600 and 630 $\mathrm{nm}$, the ratio between the fast and the slow components remains approximately 2:1. Even longer time constants may be expected for longer emission wavelengths, according to the observed trend of time constant variation observed in the three wavelengths mentioned above. The long time constant $11 \mathrm{ps}$ for the $630 \mathrm{~nm}$ transient is very similar with that reported from TCSPC experiments by Siddique et al. on $\left[\mathrm{Cu}^{\mathrm{I}}(\mathrm{dmp})_{2}\right]^{+}$where they found a prompt fluorescence lifetime attributed to the ${ }^{1} \mathrm{MLCT}$ state of $13-$ 16 ps collected at $700 \mathrm{~nm}$ (near the peak of the steady state emission band). ${ }^{34}$ It is worth noticing that the values of the fluorescence decay constants are almost the same as the two fast time constants observed in the transient absorption spectroscopy. Therefore, we observed a strong correlation of the fluorescence lifetime with the emission wavelength, with longer decay constants observed in longer 
wavelength of the emission spectrum. The implication of the time constant variation with emission wavelength will be discussed below.

\section{Discussion}

The nature of the flattening process: inner sphere vs. outer sphere structural reorganization

Because of the susceptibility of the $3 d^{9}$ configuration to Jahn-Teller distortion, the ${ }^{3}$ MLCT state of $\left[\mathrm{Cu}^{\mathrm{I}}(\mathrm{dmp})_{2}\right]^{+}$with $\mathrm{Cu}(\mathrm{II})$ character was initially suggested to have flattened tetrahedral coordination where the dihedral angle, $\varphi$, defined by the two dmp ligand planes becomes significantly smaller than $90^{\circ}{ }^{48}$ However, the dynamics of the flattening as well as the effects of surrounding solvent molecules are unclear. In our last contribution, ${ }^{31}$ we tentatively assigned the dynamics of the sub-ps time component for $\left[\mathrm{Cu}^{\mathrm{I}}(\mathrm{dmp})_{2}\right]^{+}$in acetonitrile to initial charge separation and the ISC from the $\mathrm{F}-\mathrm{C}$ ${ }^{1}$ MLCT state to the ${ }^{3}$ MLCT state, while the intermediate $10-20 \mathrm{ps}$ timescale, to the structural rearrangement, presumably the flattening and thermal equilibration (vibrational cooling). The assignment for the sub--ps time constant was based on previous works by Okada and coworkers ${ }^{36}$ and by McCusker and coworkers ${ }^{49-51}$ on $\left[\mathrm{Ru}^{\mathrm{II}}(\mathrm{bpy})_{2}\right]^{2+}$ complex in solution where the time constant for the ISC process is as fast as 40 fs. Considering the similarities on the structures and the ground state absorption spectra between the two molecules, as well as $\mathrm{Cu}$ being a lighter element than $\mathrm{Ru}$, it is conceivable that the $I S C$ in the ${ }^{1}$ MLCT state of $\left[\mathrm{Cu}^{\mathrm{I}}(\mathrm{dmp})_{2}\right]^{+}$would be slower than that of $\left[\mathrm{Ru}^{\mathrm{II}}(\mathrm{bpy})_{2}\right]^{2+}$ and fall within the sub-ps time scale. The assignment for the 10-20 ps time constant was based on the results from the TD-DFT calculations and the experimentally observed blue-shift in the excited state absorption, ${ }^{31}$ and on the time scale for the intramolecular rotational correlation time measured for some TICT (twisted intramolecular charge transfer) molecules. ${ }^{37}$ The internal rotation of the naphthalene group in bis-naphthalene in the TICT state takes about $15 \mathrm{ps},{ }^{52}$ providing an order of magnitude for the internal rotation of the dmp with a chromophore relatively larger than naphthalene. The TD-DFT calculations revealed a widening of the energy gap between the ${ }^{3}$ MLCT state and the upper excited states as the dihedral angle $\varphi$ changes from $90^{\circ}$ to $68^{\circ} .{ }^{31}$ This result was apparently in agreement with 
our experimentally observed blue-shift in the excited state absorption band within 10-15 ps after the photoexcitation. In addition, vibrational cooling is also manifested by blue shifting and narrowing of transient absorption bands and is believed to occur on a similar timescale for large molecules such as $\left[\mathrm{Cu}^{\mathrm{I}}(\mathrm{dmp})_{2}\right]^{+}$in solution. ${ }^{36,53,54}$

Table 6. Properties of the Solvents Used $\left(20^{\circ} \mathrm{C}\right)$

\begin{tabular}{ccccc} 
& dielectric constant & relaxation times & thermal diffusivity & viscosity \\
& & $\mathrm{ps}$ & $10^{-9} \mathrm{~m}^{2} / \mathrm{s}$ & $\mathrm{mPa} \cdot \mathrm{s}^{\mathrm{a}}$ \\
\hline acetonitrile & $37.50^{\mathrm{b}}$ & $0.089,0.63^{\mathrm{c}}$ & $1.08^{\mathrm{e}}$ & $0.39^{\mathrm{b}}$ \\
ethylene glycol & $37.70^{\mathrm{c}}$ & $0.187,4.98,32^{\mathrm{c}}$ & $0.975^{\mathrm{f}}$ & $19.9^{\mathrm{b}}$ \\
toluene & $2.40^{\mathrm{b}}$ & $0.157,2.16,15.21^{\mathrm{d}}$ & $0.879^{\mathrm{f}}$ & $0.59^{\mathrm{b}}$ \\
\hline
\end{tabular}

\footnotetext{
${ }^{\mathrm{a}} \mathrm{Pa}=$ Pascal.

${ }^{\mathrm{b}}$ see reference ${ }^{63}$.

${ }^{c}$ see reference ${ }^{64}$.

d see reference $65^{\circ}$.

e see reference ${ }^{66}$.

${ }^{\mathrm{f}}$ see reference ${ }^{67^{\circ}}$.
}

In the current work we extend our optical studies to $\left[\mathrm{Cu}^{\mathrm{I}}(\mathrm{dmp})_{2}\right]^{+}$in various solvents as well as one other $\mathrm{Cu}(\mathrm{I})$ bis-phenanthroline derivative, $\left[\mathrm{Cu}^{\mathrm{I}}(\mathrm{dpp})_{2}\right]^{+}$, in an effort to confirm our model that the flattening of the tetrahedral coordination causes the blue-shift in the excited state absorption. If the reduction of the angle $\varphi$ (flattening) from nearly orthogonal in the initial Franck-Condon state were an outer sphere process, it would occur in concert with solvent displacement and thus be dependent on the reorganization energetics, dynamics and viscosity of the solvent. Meanwhile, if the vibrational cooling by the solvent contributes to the blue-shift in the excited state absorption, the time constant for this event should depend upon the solvent thermal diffusivity. However, we did not observe apparent trends in the time constants of the sub-ps and 10-15 ps components associated with relevant solvent properties 
shown in Table 6 according to the transient absorption spectroscopy results. Furthermore, there appears to be essentially no difference in transient spectra collected at the same delay time among the three solutions during the first $20 \mathrm{ps}$ after the photoexcitation if the population decay related to the diverse lifetimes for $\left[\mathrm{Cu}^{\mathrm{I}}(\mathrm{dmp})_{2}\right]^{+}$on the nanosecond time scale is neglected. The peak intensity normalized transient absorption spectra in the three different solutions collected at $\sim 1.2$ ps after photoexcitation are virtually indistinguishable (Figure 12A). At 20 ps time delay, some minor differences are noticeable as the weaker band $(\sim 520 \mathrm{~nm})$ shows a somewhat more defined structure and intensity in the toluene case and the tail on the red side of the main band at $\sim 560 \mathrm{~nm}$ for the ethylene glycol spectrum is slightly more intense than the other two (Figure 12B). It is possible that these minor differences signify the strength of the solvent-solute interactions in different solvents as revealed by our previous LITR-XAS results. ${ }^{31}$ Whether these inconsistencies carry any significance is unclear, especially given that the position, shape and apparent width of the main band at $\sim 560 \mathrm{~nm}$ are nearly identical in the three solvents. What does become apparent is that the excited state dynamics of $\left[\mathrm{Cu}^{\mathrm{I}}(\mathrm{dmp})_{2}\right]^{+}$appears to be a solvent independent inner sphere process during 1-20 ps after the photoexcitation. In fact, this could be the case for $\mathrm{Cu}(\mathrm{I})$ diimine systems in general, because the results presented here are complemented by other experimental results on multiple $\mathrm{Cu}(\mathrm{I})$ bis-diimine derivatives which extend the excited state dynamics studies to at least four different solvents. ${ }^{32,34,55}$ Similar spectral evolution occurring on the same general timescale was observed in all cases. With such diverse systems and solvents, the origin of the pervasive $\sim 10-15$ ps component can likely be attributed to a process involving the one common structural factor among all the systems - the copper center. The nearly identical fast time constants of 500-700 fs and 10-15 ps in all solvents suggest an inner sphere process in early stage of the excited state dynamics, which is insensitive to solvent properties. The solvent-solute complex formation with different strength of bonding, as detected by our LITR-XAS results, ${ }^{31}$ may happen after the initial stage of the photoexcitation, which is ultimately responsible for the differences in the MLCT excited state lifetime on the nanosecond timescale. 
A recent communication from Gunaratne et $a l .{ }^{55}$ describes transient absorption experiments conducted on $\mathrm{Cu}(\mathrm{I})$ bis-phenanthrolines with $n$-hexyl or $4-n$-butylphenyl substituents at the 2,9 positions dissolved in methylene chloride. For the $n$-hexyl variant, they observe the same dynamics with nearly identical transient spectra as ours (suggesting that the alkyl substituent acts like a methyl substituent, giving the appearance of the $\mathrm{dmp}^{--}$spectrum). It is also noteworthy that the transient spectra for their 4-n-butylphenyl substituted complex bear an uncanny resemblance to our results for $\left[\mathrm{Cu}^{\mathrm{I}}(\mathrm{dpp})_{2}\right]^{+}$(Figure 8 ), including an isobestic point at approximately $665 \mathrm{~nm}$. Thus, it seems that the 4-n-butylphenyl substituents possess similar properties that affect the phenanthroline ligands of the photoexcited complex in much the same way as the unsubstituted phenyl rings of the $\left[\mathrm{Cu}^{\mathrm{I}}(\mathrm{dpp})_{2}\right]^{+}$ complex. Interestingly, they also observe a 15 ps blue shifting component that is independent of ligand substituent and occurs in $\mathrm{CH}_{2} \mathrm{Cl}_{2}$. Here we present two more examples of $\mathrm{Cu}(\mathrm{I})$ bis-phenanthroline complexes for which we have different ligands and a fourth solvent system, yet we observe the same timescale for the blue shift. The only constant in our observations and those of Gunaratne et al. is the fact that both studies are on $\mathrm{Cu}(\mathrm{I})$ systems, which supports assignment of a process that is related to the metal center, such as intersystem crossing.

How fast is the flattening of the ${ }^{1} \mathrm{MLCT}$ state of $\left[\mathrm{Cu}(\mathrm{dmp})_{2}\right]^{+}$?

Our goal in this study is to answer a key question about how fast the tetrahedral F-C excited state structural flattening takes place, i.e. how fast is the geometry change that transforms the dihedral angles between two dmp planes in $\left[\mathrm{Cu}^{\mathrm{I}}(\mathrm{dmp})_{2}\right]^{+}$from $90^{\circ}$ to $68^{\circ} .{ }^{31}$ Although the excited state absorption blueshift that occurs within 10-15 ps of the excitation could be correlated with the energy gap increase between the lowest energy excited state to upper excited states that arises due to the flattening of a tetrahedral geometry, the completeness of this model is called into question by the result of fluorescence lifetime measurements for $\left[\mathrm{Cu}(\mathrm{dmp})_{2}\right]^{+}$by Siddique et al. ${ }^{34}$ They obtained a fluorescence lifetime of 13-16 ps in acetonitrile at room temperature, implying an unexpectedly slow ISC process on that time scale for the ${ }^{1} \mathrm{MLCT}$ state $\left(\mathrm{S}_{1}\right)$ of $\left[\mathrm{Cu}^{\mathrm{I}}(\mathrm{dmp})_{2}\right]^{+}$. The rationale for such a slow ISC process in comparison with that of $\left[\mathrm{Ru}^{\mathrm{II}}(\mathrm{bpy})_{3}\right]^{2+}$ at $40 \mathrm{fs}$, according to Siddique $e$ et $a{ }^{34}{ }^{34}$ is due to weakened spin- 
orbital coupling as the result of the structural rearrangement in the $\mathrm{S}_{1}$ state, namely the flattening of the tetrahedral geometry of the F-C state via the decrease of $\varphi .^{34}$ Based on the TD-DFT calculations and the fluorescence lifetime measurements by TCSPC, they concluded that the flattening occurred prior to the ISC process rather than vice versa. However, the time scale of the flattening is still unclear because of the time resolution limit of the TCSPC technique. ${ }^{56}$ Meanwhile, the ISC process from a higher energy ${ }^{1} \mathrm{MLCT}$ state to the lower energy ${ }^{3} \mathrm{MLCT}$ state could also cause the increase of the energy gap between the ${ }^{3}$ MLCT state and the upper states, resulting in a blue-shift in the excited state absorption as observed in the transient absorption spectroscopy. Hence, both flattening of the tetrahedral F-C state and the ISC will cause the blue-shift in the excited state absorption (Figure 13), and the transient blueshift in $10-15$ ps after excitation is not necessarily due to the flattening, if Nozaki's model is correct.

In this report, we intend to investigate the excited state dynamics with a much better time resolution than TCSPC by both femtosecond transient absorption and fluorescence upconversion measurements. More importantly, we hope the complementary dynamic information from the two measurements will bring new insight into the time scales of the structural rearrangements, especially the flattening, because the former samples the transitions from the lowest excited state to other upper states, whereas the latter samples the transitions from the lowest excited state to the ground state (Figure 13).

Extensive TD-DFT calculations ${ }^{31,33,34}$ have provided valuable information about the symmetry, electronic structure and energetics of the molecular orbitals and excited states of photoexcited $\left[\mathrm{Cu}^{\mathrm{I}}(\mathrm{dmp})_{2}\right]^{+}$. The TD-DFT results indicate that because of orbital symmetry, the $\left[\mathrm{Cu}^{\mathrm{I}}(\mathrm{dmp})_{2}\right]^{+}$MLCT transition centered at $\sim 460 \mathrm{~nm}$ in the steady state absorption spectrum does not populate the lowest energy ${ }^{1}$ MLCT state $\left(\mathrm{S}_{1}\right)$. Thus the F-C MLCT state is actually a higher singlet that undergoes internal conversion (IC) to $\mathrm{S}_{1}$, probably on an ultrafast timescale $(<1 \mathrm{ps})$. These calculations predict that $\mathrm{S}_{1}$ and the one of the low energy ${ }^{3}$ MLCT states are nearly isoenergetic. Siddique et al. also calculated the spin-orbit integrals between the ${ }^{1}$ MLCT and ${ }^{3}$ MLCT states, which provide unique insights into the ISC mechanism. $^{34}$ They found that spin-orbit coupling between the F-C MLCT state and the lowest ${ }^{3} \mathrm{MLCT}$ state $\left(\mathrm{T}_{1}\right)$ is fairly strong $\left(\sim 300 \mathrm{~cm}^{-1}\right)$, so IC to $\mathrm{S}_{1}$ probably competes with fast ISC to $\mathrm{T}_{1}$ at very 
early times after photoexcitation. However, when the dihedral angle between the ligands $\varphi$ decreases to the MLCT state geometry, the orbital energies for higher triplet states lie above the lowest energy singlet. So the only energetically favorable pathway for $I S C$ to occur is from $S_{1}$ to the lower energy ${ }^{3}$ MLCT states. But their calculations found that the spin-orbit coupling between these states arises primarily from ligand-centered orbitals and is thus much weaker $\left(\sim 30 \mathrm{~cm}^{-1}\right)$. Consequently, once structural rearrangement begins to occur, ISC to the triplet manifold becomes slower than one might expect.

As displayed in Figure 12, the fluorescence decay kinetics from the fluorescence upconversion measurements are strongly emission wavelength dependent. According to Zgierski's calculation, ${ }^{33}$ the photoexcitation at $468 \mathrm{~nm}$ results in a transition from $\mathrm{S}_{0} \rightarrow \mathrm{S}_{3}$, where $\mathrm{S}_{3}$ is an upper singlet state, whereas the direct transition from $\mathrm{S}_{0} \rightarrow \mathrm{S}_{1}$ (the lowest fluorescing singlet state) is symmetry forbidden. Siddique et al. also noted that the calculated results are very sensitive to the dihedral angle between the dmp rings. It is worth noticing that a recent review showed that TD-DFT sometimes incorrectly estimated the vertical transition energies for certain charge-transfer processes. ${ }^{57}$ This review cautions TD-DFT users to calibrate their results against other techniques, especially CIS(D) methods. If Zgierski's TDDFT results ${ }^{33}$ are correct regarding negligible direct excitation to the $S_{1}$ and $S_{2}$ states, the time evolution of the $S_{1}$ population probed by fluorescence upconversion can be expressed as:

$$
\begin{aligned}
\frac{d\left[S_{1}(t)\right]}{d t} & =k_{i c}[\varphi(t)] \cdot\left[S_{3}(t)\right]-\left\{k_{r}[\varphi(t)]+k_{n r}[\varphi(t)]+k_{i s c}[\varphi(t)]\right\} \cdot\left[S_{1}(t)\right] \\
& =\frac{\left[S_{3}(t)\right]}{\tau_{i c}}-\frac{\left[S_{1}(t)\right]}{\tau[\varphi(t)]}
\end{aligned}
$$

where $\varphi(t)$ is simplified reaction coordinates representing mainly the dihedral angle between the two dmp planes; $k_{I C}, k_{r}, k_{n r}$, and $k_{I S C}$ are rate constants respectively for internal conversion from $\mathrm{S}_{3}$ to $\mathrm{S}_{1}$, fluorescence decay from $S_{1}$ to $S_{0}$, internal conversion from $S_{1}$ to $S_{0}$, and intersystem crossing from $S_{1}$ to $\mathrm{T}_{1}$, and $\boldsymbol{\tau}$ is the fluorescence decay time constant. Equation (1) summarizes the different channels transferring population to and from the $S_{1}$ state. Most importantly, it demonstrates complications in 
obtaining an analytical solution for a direct comparison with the fluorescence upconversion results, because all above rate constants are correlated with $\varphi(t)$ as an unknown function of $t$. Without accurate measurement of the $\mathrm{S}_{1}(\mathrm{t})$ at different delay times, it seems unlikely to be able to obtain the flattening dynamics directly.

As an approximation, we could extract $\tau$ as a function of $\varphi(t)$ based on experimental data and a pseudo-harmonic oscillator model, assuming $E\left(S_{1}\right)=1 / 2 D \varphi^{2}$, where $E\left(S_{1}\right)$ is the energy on the $S_{1}$ potential surface (Figure 12), and D, the "force constant" of the harmonic oscillator. This approximation considered the path from the initial dihedral angle at the F-C state at $90^{\circ}$ to the final value of $68^{\circ}$ based on our previous TD-DFT calculation. ${ }^{34}$ Assuming $\mathrm{E}\left(\mathrm{S}_{1}\right)_{1}\left(\lambda_{1}=550 \mathrm{~nm}\right)=18,181 \mathrm{~cm}^{-1}$, and $\boldsymbol{\varphi}_{1}=\pi / 2$ as the starting point of the dihedral angle in the F-C state corresponding to the blue-most emission, the "force constant" D is $14,740 / \mathrm{cm}^{\prime} \mathrm{rad}^{2}$. We could then extract the corresponding $\varphi$ at 600 and $630 \mathrm{~nm}$ emission wavelengths, and therefore, obtain a numerical relationship between $\tau$ and $\boldsymbol{\varphi}$ (Figure 14). The final value of $\varphi$ is $68^{\circ}$, and long component of $\tau$ is 13 ps based on the results from our study $^{31}$ as well as that from Siddique et al.. ${ }^{34}$ In spite of limited data points from the upconversion experiment, Figure 14 already suggests biphasic dependence of $\tau$ on $\varphi$, indicating a more complex potential surface than the one shown in the previous work. ${ }^{34}$

At the blue-edge of the fluorescence spectrum, i.e. $550 \mathrm{~nm}$, the fluorescence decay kinetics has dualexponential decay kinetics with a dominant (95\%) component of $66 \mathrm{fs}$, representing the prompt fluorescence lifetime when the excited state molecule has a near F-C state geometry with $\varphi \sim 90^{\circ}$. The prompt fluorescence decay is convoluted with the internal conversion from $S_{3}$ to $S_{1}$ which is expected to generate the rise of the fluorescence from the $S_{1}$ state population. Although no rise component could be extracted from the experimental data (Figure 12), the decay time constant of 66 fs provides an upper limit for the internal conversion time constant, $\tau_{I C}=1 / k_{I C}$, which must be shorter than 66 fs in order to accumulate the $S_{1}$ state population. The ultrashort fluorescence lifetime is comparable with the 40 fs fluorescence lifetime of $\left[\mathrm{Ru}^{\mathrm{II}}(\mathrm{bpy})_{2}\right]^{2+}$ revealed by the first fluorescence upconversion measurement on transition metal complexes, and can be well-understood considering that a weaker spin-orbital coupling 
is expected for $\mathrm{Cu}(\mathrm{II})^{*}\left(3 d^{9}\right)$ in the excited $\left[\mathrm{Cu}^{\mathrm{I}}(\mathrm{dmp})_{2}\right]^{+}$than for $\mathrm{Ru}(\mathrm{III})^{*}\left(4 d^{5}\right)$ in the excited $\left[\mathrm{Ru}\left(\mathrm{II}(\mathrm{bpy})_{3}\right]^{+2}\right.$. However, further complication comes from the electronic configuration induced structural changes, the Jahn-Teller distortion in the former, whereas that is absent in the latter. Because of the significant structural reorganization of the MLCT state of $\left[\mathrm{Cu}^{\mathrm{I}}(\mathrm{dmp})_{2}\right]^{+}$, the electronic couplings between the initially excited state and other states will vary with the reaction coordinates, resulting in excited state structural dependent rate constants as shown in Equation (1).

The ultrafast fluorescence decay with two components of 66 fs (95\%) and 471 fs (5\%) time constants at $550 \mathrm{~nm}$, on the blue side of the emission spectrum, evolves into dual-exponential decays at longer emission wavelengths with time constants of $260 \mathrm{fs}(66 \%)$ and $1.17 \mathrm{ps}(34 \%)$ at $600 \mathrm{~nm}$, and those of $730 \mathrm{fs}(70 \%)$ and $11 \mathrm{ps}(30 \%)$ at $630 \mathrm{~nm}$. The trend of increasing fluorescence decay time constants could continue to longer emission wavelengths and to conceivably merge to the value observed by the previous TCSPC measurements with a 13-ps fluorescence decay time constant. ${ }^{34}$ At these longer emission wavelengths the ${ }^{1}$ MLCT state could have flattened coordination geometry with weakened spin-orbital coupling as calculated by Siddique et al., ${ }^{34}$ resulting in longer time constants for ISC.

Although the direct measurement of the flattening time is difficult considering the structural dependent decay rate constants on the excited state potential surface, the fluorescence decay kinetics measured by the fluorescence upconversion at different emission wavelengths revealed much faster components missed by the TCSPC measurements, ${ }^{34}$ which provide the upper limit for the time constants. That is to say that the flattening must be approximately as fast as the fluorescence decay in order to enable the survival population of $\mathrm{S}_{1}$ to correlate with the thermally equilibrated geometry. The fluorescence upconversion results enable us to realize that the previous tentative assignments on 10-15 ps flattening and $0.5-0.7 \mathrm{ps} I S C$ time constants from the transient absorption were based on insufficient experimental results. Our new interpretation is that the flattening should be occurring on the order of about 100 fs. 
The dual-exponential fluorescence decay components observed at 600 and $630 \mathrm{~nm}$ emission may indicate a more complicated potential surface for the excited state. So far, we mainly focused on the effect of the dihedral angle on the excited state decay kinetics. In reality, it may be more complicated due to the structural relaxation of the excited molecule with other degrees of freedom, such as concerted rocking of the two dmp ligands, changes in bond lengths or solvent ligation. Therefore, it is very likely that the slow component observed in the fluorescence transients at 600 and $630 \mathrm{~nm}$ is due to ISC while the faster component is due to structural relaxation including the flattening of the dihedral angle that depletes the $\mathrm{S}_{1}$ population.

\section{Why the biphasic blue shift was not observed in the transient absorption spectra}

Based on the above discussion, both flattening and ISC should cause a widening of the energy gap between the excited state to higher-lying excited states, which should be observed by the transient absorption as the blue shift in the spectral region from 480 to $700 \mathrm{~nm}$. The previous calculation suggested a blue-shift of about $80 \mathrm{~nm}$ due to the flattening that changes $\varphi$ from $90^{\circ}$ to $68^{\circ} .^{31}$ However, the observed blue-shift in the transient absorption measurements is much smaller than that and is on a similar time scale as the slow component of the fluorescence upconversion data which has been assigned as the ISC process, while no blue-shift was observed on the sub-ps time scale, even though the TD-DFT calculations suggested such a shift. ${ }^{31}$ Therefore, the transient absorption measurements did not capture the blue-shift in the excited state absorption corresponding to the flattening whereas the fluorescence upconversion will only probe transitions involving the $S_{1}$ state. Because of the complicated structural dynamics and the structural dependent kinetics, the excited state absorption spectra include various transitions from both $S_{1}$ and $T_{1}$ to other upper excited states with intertwined interconversion kinetics. The initial broad and featureless transient absorption spectra in the three solvents studied here shows such a possibility. In addition, the three time constants obtained from the fitting of multiple exponentials is based on a discrete single species model, which may not be appropriate to describe the structural dependent kinetics encountered here. The absorption band in the 
1.2 ps spectra (Figure, upper panel) is centered at approximately $568 \mathrm{~nm}$ and the more intense band in the $20 \mathrm{ps}$ spectra (Figure, lower panel) is centered at $560 \mathrm{~nm}$. This blue shift corresponds to an energy difference of $0.057 \mathrm{eV}$. If Zgierski's TD-DFT calculations on photoexcited $\left[\mathrm{Cu}^{\mathrm{I}}(\mathrm{dmp})_{2}\right]^{+}$is correct, the energy gap between the lowest singlet excited state and the highest of the low energy triplet states is $0.0531 \mathrm{eV}^{33}$ This energy change observed in the blue shift of the absorption maxima seems to correspond to this energy gap involved, assuming the energy gap remains approximately the same with the excited state geometry.

\section{Conclusions}

The MLCT excited states of $\mathrm{Cu}(\mathrm{I})$ diimine molecules exhibit rich photophysics and complicated dynamics, especially at very early times after photoexcitation. In the current work we have attempted to clarify the timescales for the various relaxation processes in these complexes by performing ultrafast transient absorption experiments on $\left[\mathrm{Cu}^{\mathrm{I}}(\mathrm{dmp})_{2}\right]^{+}$in various solvents with distinct physical properties (acetonitrile, ethylene glycol and toluene) as well as on a closely related complex $\left[\mathrm{Cu}^{\mathrm{I}}(\mathrm{dpp})_{2}\right]^{+}$with bulkier ligands in acetonitrile. Based on our previous tentative assignment that the blue shift of the transient absorption band within 10-15 ps was an evidence of structural reorganization involving significant displacement of the ligands as well as their environment, ${ }^{31}$ we expected to observe different timescales for the spectral evolution in the various solvents that corresponded to their relaxation dynamics and viscosity. However, we found that the timescale for the spectral evolution was $\sim 10-15 \mathrm{ps}$ in all cases - independent of the solvent or the substituent. It appears that the relaxation path from the F-C ${ }^{1}$ MLCT (where the ligand planes are essentially orthogonal) state to the thermally equilibrated

${ }^{3}$ MLCT state (where the dihedral angle between the ligand planes is reduced and the molecule is "flattened") is more complicated than portrayed in our previous model. The irrelevance of the solvent (and substituent) on the timescales for the spectral evolution can be interpreted in two ways: 1) the flattening of the molecule is totally an inner sphere process, thus would not be affected by the bulk solvent properties because only a few solvent molecules are in the proximity of the ligands; or 2) the 
$\sim 10-15$ ps timescale of the spectral evolution is the manifestation of another process. Our current results, in conjunction with the other experimental and theoretical ${ }^{31,33,34}$ evidence point to the latter interpretation. Based on the solvent independent kinetics, the observed spectral evolution and its associated $\sim 10-15 \mathrm{ps}$ timescale are assigned to ISC from the ${ }^{1} \mathrm{MLCT}$ states to the manifold of ${ }^{3} \mathrm{MLCT}$ states. This process is slower than other similar coordination complexes because of the structural distortion that occurs in these $\left[\mathrm{Cu}^{\mathrm{I}}(\mathrm{NN})_{2}\right]^{+}$systems.

Meanwhile, the ${ }^{1}$ MLCT state structural dynamics as probed by fluorescence upconversion reveals an ultrafast prompt fluorescence decay near the F-C geometry. The variation of the dual-exponential fluorescence decay functions with the emission wavelength suggested a structure-dependent excited state dynamics. At longer emission wavelength, the long time constant agrees with the previous TCSPC results, while the short time constant that dominates the fluorescence decay is likely due to the structural relaxation. If the main pathway for ${ }^{1} \mathrm{MLCT}$ state to survive to the thermally equilibrated structure is to have very fast distortion that would slow down the ISC, such a distortion, the "flattening" of the tetrahedral F-C state geometry, must take place on the same timescale as the prompt fluorescence, i.e. 60 fs. The extra energy that the ${ }^{1}$ MLCT state possesses enables the torsional motion ("flattening") between the two rather large ligands much faster than we expected by the ligand of similar sizes in the ground state.

Our results show that optical methods are probing the structural changes indirectly, and the optical signals originating from different transient species often overlap with one another. This is exemplified by the fact that the transient absorption at $\sim 560 \mathrm{~nm}$ is a $\pi-\pi^{*}$ transition localized on the $\mathrm{dmp}^{\circ}$ ligand. $^{58,59}$ In the simplest approximation, there should not be any difference in this transition that depends on the dihedral angle between the two ligand planes. Of course, the energetics and symmetries of the orbitals giving rise to this $\pi-\pi^{*}$ transition are considerably more complex than this, but it typifies the basic problem associated with using optical methods to learn about the structural rearrangement in $\left[\mathrm{Cu}^{\mathrm{I}}(\mathrm{dmp})_{2}\right]^{+}$. Ultimately, we can extract excited state structural dynamics through direct structural 
determination on the time scale of the structural changes using pulsed x-rays or electrons. In the previous studies $\mathrm{x}$-ray pulses from a $3^{\text {rd }}$ generation synchrotron source were used to probe the structure of the flattened and ligated excited state, ${ }^{30,31,60-62}$ but these pulses are too long $(\sim 100 \mathrm{ps})$ to follow the fast atomic motions involved with the structural rearrangement and exciplex formation in $\left[\mathrm{Cu}^{\mathrm{I}}(\mathrm{dmp})_{2}\right]^{+}$ revealed in this report. When much shorter pulse ultrafast x-ray sources with sufficient flux are successfully implemented in the future, ${ }^{\text {ii }}$ it will be possible to directly observe the changing excited state structures and photochemical adducts with picosecond to femtosecond resolution.

\section{Acknowledgements}

This work is supported at Argonne National Laboratory by the Division of Chemical Sciences, Office of Basic Energy Sciences, the U.S. Department of Energy under contract W-31-109-Eng-38 (LXC and GBS), and at Johns Hopkins University by the same sponsor with the grant DE-FG02-96ER14662 (GJM). The work at Rutgers University was supported by the National Science Foundation grant CHE0239390. The authors would like to thank Professor Philip Coppens for insightful discussions, and Dr. Irina Novozhilova for her help in examining previous calculated results. CDG wishes to acknowledge the support during the completion of this manuscript by Livermore National Laboratory under the auspices of the U.S. Department of Energy by University of California, Lawrence Livermore National Laboratory under Contract W-7405-Eng-48.

ii There are several fast X-ray sources being built in the US and abroad which can be found in several recent workshops in various locations. See ref. 60 for a partial listing. 


\section{References}

(1) McMillin, D. R.; Kirchhoff, J. R.; Goodwin, K. V., Coord. Chem. Rev. 1985, 64, 83-92.

(2) Casadonte, D. J., Jr.; McMillin, D. R., Inorg. Chem. 1987, 26, 3950-2.

(3) Cunningham, C. T.; Cunningham, K. L. H.; Michalec, J. F.; McMillin, D. R., Inorg.

Chem. 1999, 38, 4388-4392.

(4) Ichinaga, A. K.; Kirchhoff, J. R.; McMillin, D. R.; Dietrich-Buchecker, C. O.; Marnot, P. A.; Sauvage, J. P., Inorg. Chem. 1987, 26, 4290-2.

(5) Kirchhoff, J. R.; Gamache, R. E., Jr.; Blaskie, M. W.; Del Paggio, A. A.; Lengel, R. K.; McMillin, D. R., Inorg. Chem. 1983, 22, 2380-4.

(6) Palmer, C. E. A.; McMillin, D. R.; Kirmaier, C.; Holten, D., Inorg. Chem. 1987, 26, $3167-70$.

(7) Miller, M. T.; Ganzel, P. K.; Karpishin, T. B., J. Am. Chem. Soc. 1999, 121, 4292.

(8) Scaltrito, D. V.; Fry, H. C.; Showalter, B. M.; Thompson, D. W.; Liang, H.-C.; Zhang, C. X.; Kretzer, R. M.; Kim, E.-i.; Toscano, J. P.; Karlin, K. D.; Meyer, G. J., Inorg. Chem. 2001, 40, 45144515.

(9) Ruthkosky, M.; Kelly, C. A.; Castellano, F. N.; Meyer, G. J., Coord. Chem. Rev. 1998, $171,309-322$.

(10) Castellano, F. N.; Meyer, G. J., Prog. Inorg. Chem. 1997, 44, 167-208.

(11) Armaroli, N.; Diederich, F.; Echegoyen, L.; Habicher, T.; Flamigni, L.; Marconi, G.; Nierengarten, J. F., New J. Chem. 1999, 23, 77-83.

(12) Ruthkosky, M.; Kelly, C. A.; Zaros, M. C.; Meyer, G. J., J. Am. Chem. Soc. 1997, 119, 12004-12005.

(13) Thanasekaran, P.; Liao, R. T.; Liu, Y. H.; Rajendran, T.; Rajagopal, S.; Lu, K. L., Coord. Chem. Rev. 2005, 249, 1085-1110.

(14) Vannelli, T. A.; Karpishin, T. B., Inorg. Chem. 2000, 39, 1336-1336. 
(15) Armaroli, N.; Balzani, V.; Barigelletti, F.; Decola, L.; Flamigni, L.; Sauvage, J. P.;

Hemmert, C., J. Am. Chem. Soc. 1994, 116, 5211-5217.

(16) Collin, J.-P.; Dietrich-Buchecker, C.; Gavina, P.; Jimenez-Molero, M. C.; Sauvage, J.-P., Acc. Chem. Res. 2001, 34, 477-487.

(17) Sauvage, J.-P., Science 2001, 291, 2105-2106.

(18) Armaroli, N., Chem. Soc. Rev. 2001, 30, 113-124.

(19) Kirchhoff, J. R.; McMillin, D. R.; Robinson, W. R.; Powell, D. R.; McKenzie, A. T.; Chen, S., Inorg. Chem. 1985, 24, 3928-33.

(20) Palmer, C. E. A.; McMillin, D. R., Inorg. Chem. 1987, 26, 3837-40.

(21) Berger, R. M.; McMillin, D. R.; Dallinger, R. F., Inorg. Chem. 1987, 26, 3802-5.

(22) Blasse, G.; Breddels, P. A.; McMillin, D. R., Chem. Phys. Lett. 1984, 109, 24-6.

(23) Cunningham, K. L.; Hecker, C. R.; McMillin, D. R., Inorg. Chim. Acta 1996, 242, 143-7.

(24) Cunningham, C. T.; Moore, J. J.; Cunningham, K. L. H.; Fanwick, P. E.; McMillin, D. R., Inorg. Chem. 2000, 39, 3638-3644.

(25) Eggleston, M. K.; McMillin, D. R.; Koenig, K. S.; Pallenberg, A. J., Inorg. Chem. 1997, $36,172-176$.

(26) Crane, D. R.; DiBenedetto, J.; Palmer, C. E. A.; McMillin, D. R.; Ford, P. C., Inorg. Chem. 1988, 27, 3698-700.

(27) Meadows, K. A.; Liu, F.; Sou, J.; Hudson, B. P.; McMillin, D. R., Inorg. Chem. 1993, $32,2919-23$.

(28) Dietrich-Buchecker, C. O.; Marnot, P. A.; Sauvage, J. P.; Kirchoff, J. R.; McMillin, D. R., J. Chem. Soc., Chem. Commun. 1983, 513-15.

(29) Scaltrito, D. V.; Thompson, D. W.; O'Callaghan, J. A.; Meyer, G. J., Coord. Chem. Rev. 2000, 208, 243-266. 
(30) Chen, L. X.; Jennings, G.; Liu, T.; Gosztola, D. J.; Hessler, J. P.; Scaltrito, D. V.; Meyer, G. J., J. Am. Chem. Soc. 2002, 124, 10861-10867.

(31) Chen, L. X.; Shaw, G. B.; Novozhilova, I.; Liu, T.; Jennings, G.; Attenkofer, K.; Meyer, G. J.; Coppens, P., J. Am. Chem. Soc. 2003, 125, 7022-7034.

(32) Cody, J.; Dennisson, J.; Gilmore, J.; VanDerveer Donald, G.; Henary Maged, M.;

Gabrielli, A.; Sherrill, C. D.; Zhang, Y.; Pan, C.-P.; Burda, C.; Fahrni Christoph, J., Inorg. Chem. 2003, $42,4918-29$.

(33) Zgierski, M. Z., J. Chem. Phys. 2003, 118, 4045-4051.

(34) Siddique, Z. A.; Yamamoto, Y.; Ohno, T.; Nozaki, K., Inorg. Chem. 2003, 42, 63666378.

(35) Coppens, P.; Novozhilova, I., Intl. J. Quant. Chem. 2005, 101, 611-623.

(36) Bhasikuttan, A. C.; Suzuki, M.; Nakashima, S.; Okada, T., J. Am. Chem. Soc. 2002, 124, 8398-8405.

(37) Rettig, W., Photoinduced Charge Separation Via Twisted Intramolecular ChargeTransfer States. In Electron Transfer I, 1994; Vol. 169, pp 253-299.

(38) Van Meerssche, M.; Germain, G.; Declercq, J. P., Cryst. Struc. Comm. 1981, 10, 47-53.

(39) Tran, D.; Skelton, B. W.; White, A. H.; Laverman, L. E.; Ford, P. C., Inorg. Chem. 1998, $37,2505-2511$

(40) Miller, M. T.; Gantzel, P. K.; Karpishin, T. B., Inorg. Chem. 1998, 37, 2285-2290.

(41) Blaskie, M. W.; McMillin, D. R., Inorg. Chem. 1980, 19, 3519-22.

(42) Greenfield, S. R.; Wasielewski, M. R., Optics Letters 1995, 20, 1394-1396.

(43) Castner, E. W.; Kennedy, D.; Cave, R. J., J. Phys. Chem. A 2000, 104, 2869-2885.

(44) Shirota, H.; Castner, E. W., J. Chem. Phys. 2000, 112, 2367-2376.

(45) Frauchiger, L.; Shirota, H.; Uhrich, K. E.; Castner, E. W., J. Phys. Chem. B 2002, 106, 7463-7468. 
(46) English, D. S.; Das, K.; Ashby, K. D.; Park, J.; Petrich, J. W.; Castner, E. W., J. Am. Chem. Soc. 1997, 119, 11585-11590.

(47) Szabo, A., J. Chem. Phys 1984, 81, 150-167.

(48) McMilllin, D. R.; McNett, K. M., Chem. Rev. 1998, 98, 1201-1219.

(49) Damrauer, N. H.; Cerullo, G.; Yeh, A.; Boussie, T. R.; Shank, C. V.; McCusker, J. K., Science 1997, 275, 54-57.

(50) Yeh, A.; Shank, C. V.; McCusker, J. K., Science 2000, 289, 935-938.

(51) Damrauer, N. H.; McCusker, J. K., J. Phys. Chem. A 1999, 103, 8440 - 8446.

(52) Onkelinx, A.; De Schryver, F. C.; Viaene, L.; Van der Auweraer, M.; Iwai, K.;

Yamamoto, M.; Ichikawa, M.; Masuhara, H.; Maus, M.; Rettig, W., J. Am. Chem. Soc. 1996, 118, 2892 $-2902$.

(53) Tan, X.; Gustafson, T. L.; Lefumeux, C.; Burdzinski, G.; Buntinx, G.; Poizat, O., J. Phys. Chem. A 2002, 106, 3593-3598.

(54) Myers, A. B.; Rodier, J.-M.; Phillips, D. L., Jerusalem Symposia on Quantum Chemistry and Biochemistry 1994, 26, 261-78.

(55) Gunaratne, T.; Rodgers, M. A. J.; Felder, D.; Nierengarten, J. F.; Accorsi, G.; Armaroli, N., Chem. Comm. 2003, 3010-3011.

(56) Erdmann, R.; Enderlein, J.; Wahl, M., Time correlated single-photon counting and fluorescence spectroscopy. John Wiley \& Sons: 2006.

(57) Dreuw, A.; Head-Gordon, M., Chem. Rev. 2005, 105, 4009-4037.

(58) Mulazzani, Q. G.; Emmi, S.; Fuochi, P. G.; Venturi, M.; Hoffman, M. Z.; Simic, M. G., J. Phys. Chem. 1979, 83, 1582-1590.

(59) Gordon, K. C.; McGarvey, J. J., Inorg. Chem. 1991, 30, 2986-2989.

(60) Chen, L. X., Ann. Rev. Phys. Chem. 2005, 56, 221-254.

(61) Chen, L. X., Angew. Chemie, Intl. Ed. 2004, 43, 2886-2905. 
(62) Chen, L. X., Faraday Diss. 2002, 122, 315-329.

(63) Handbook of Chemistry and Physics. 72nd ed.; CRC Press: Boca Raton, FL: 1991.

(64) Horng, M. L.; Gardecki, J. A.; Papazyan, A.; Maroncelli, M., J. Phys. Chem. 1995, 99, 17311-17337.

(65) Reynolds, L.; Gardecki, J. A.; Frankland, S. J. V.; Horng, M. L.; Maroncelli, M., J. Phys. Chem. 1996, 100, 10337-10354.

(66) Kovalenko, S. A.; Schanz, R.; Hennig, H.; Ernsting, N. P., J. Chem. Phys. 2001, 115, $3256-3273$.

(67) Iwata, K.; Hamaguchi, H., J. Phys. Chem. A 1997, 101, 632-637. 
Chart 1. A) Two dimensional representations of copper(I) bis-phenanthroline derivatives used in this work; and B) the photoreaction pathways based on previous studies. $3,8,25,30,31,62$

A
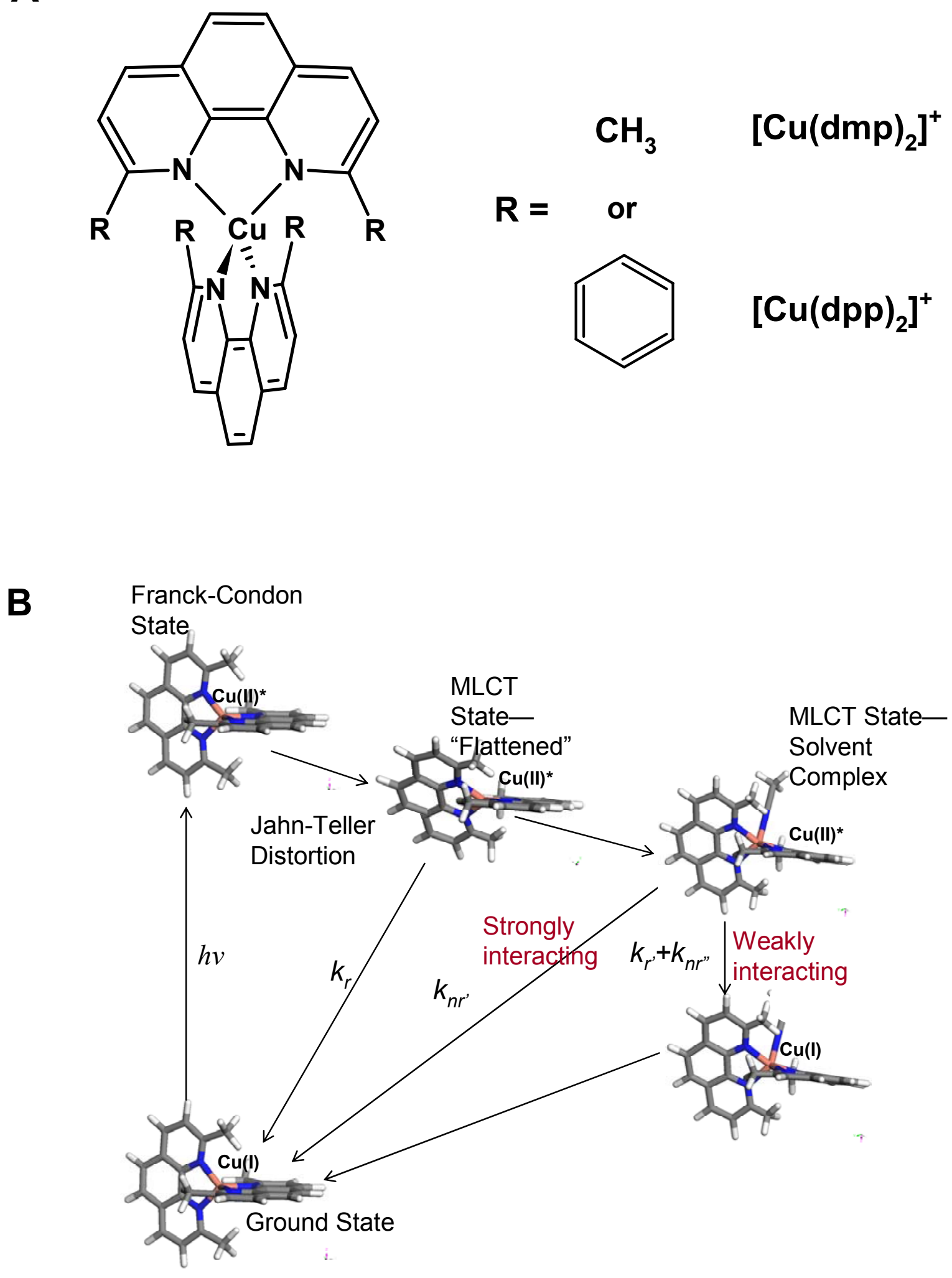


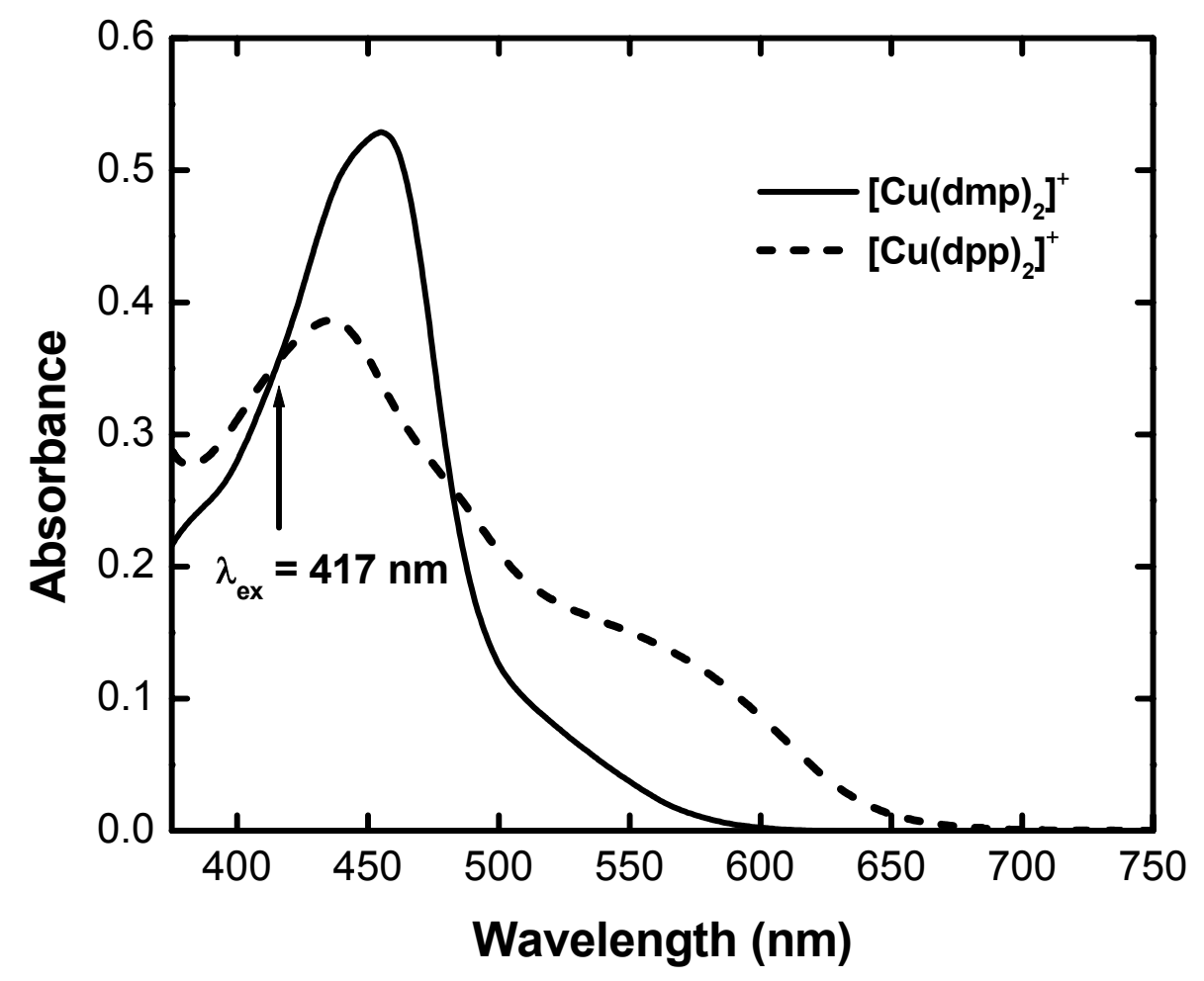

Figure 1. Ground state UV-Vis absorption spectra for $\left[\mathrm{Cu}^{\mathrm{I}}(\mathrm{dmp})\right]^{+}$and $[\mathrm{Cu}(\mathrm{Ipp})]^{+}$in acetonitrile. The spectra for $\left[\mathrm{Cu}^{\mathrm{I}}(\mathrm{dmp})\right]^{+}$in ethylene glycol and toluene perfectly overlaid the spectrum in acetonitrile and thus are not shown. The $417 \mathrm{~nm}$ pump excitation is also indicated for the transient absorption measurements, whereas the excitation wavelength for the upconversion experiment is $418.5 \mathrm{~nm}$. 


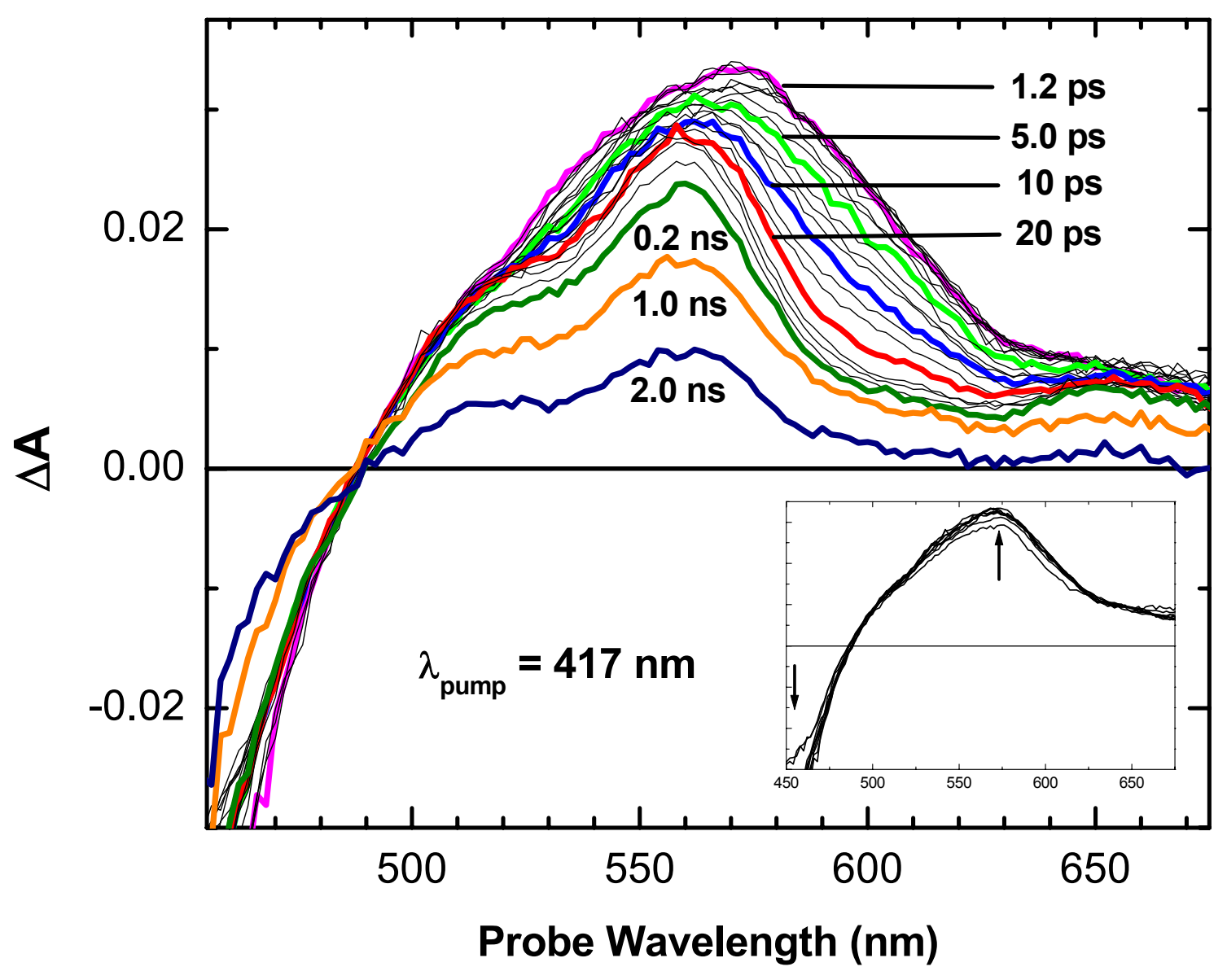

Figure 2. Transient spectra of $\left[\mathrm{Cu}(\mathrm{dmp})_{2}\right]^{+}$in acetonitrile from $1.2 \mathrm{ps}$ to $2.0 \mathrm{~ns}$. The inset shows earlier spectra from 0.3 to $1.0 \mathrm{ps}$ that correspond to the ${ }^{1} \mathrm{MLCT}$ state. The arrows on the inset spectra indicate that the excited state absorption band $(\sim 480$ to $620 \mathrm{~nm})$ and ground state bleach $(<480 \mathrm{~nm})$ are growing during the first picosecond. 


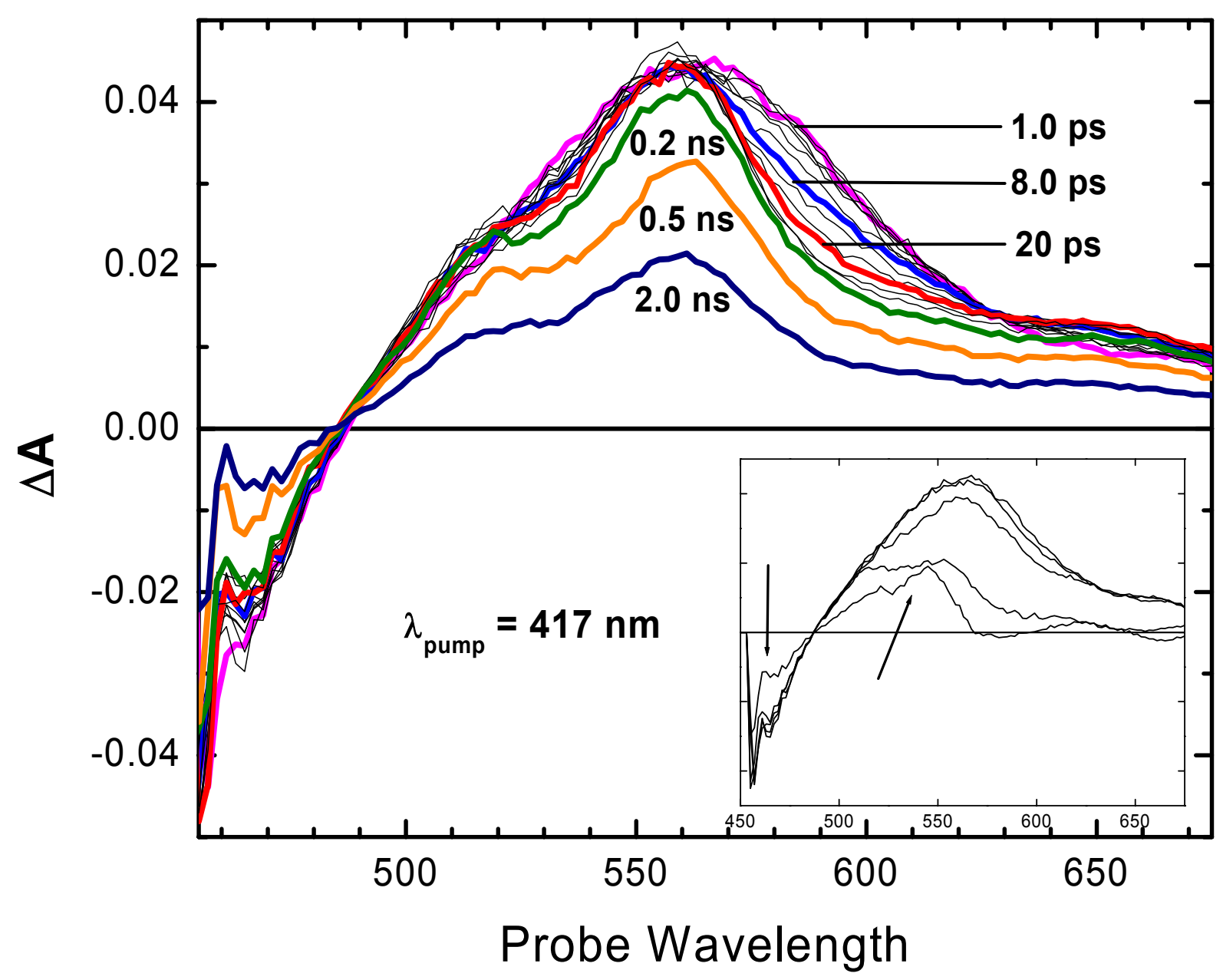

Figure 3. Transient spectra of $\left[\mathrm{Cu}(\mathrm{dmp})_{2}\right]^{+}$in ethylene glycol from 1.0 ps to $2.0 \mathrm{~ns}$. The inset shows earlier spectra from 0.2 to $1.0 \mathrm{ps}$. The right hand arrow on the inset spectra indicates that the initial growth for the transient absorption is shifting to the red as it grows during the first few hundred femtoseconds. This initial growth was not seen in the acetonitrile case and is opposite of the direction in toluene. 


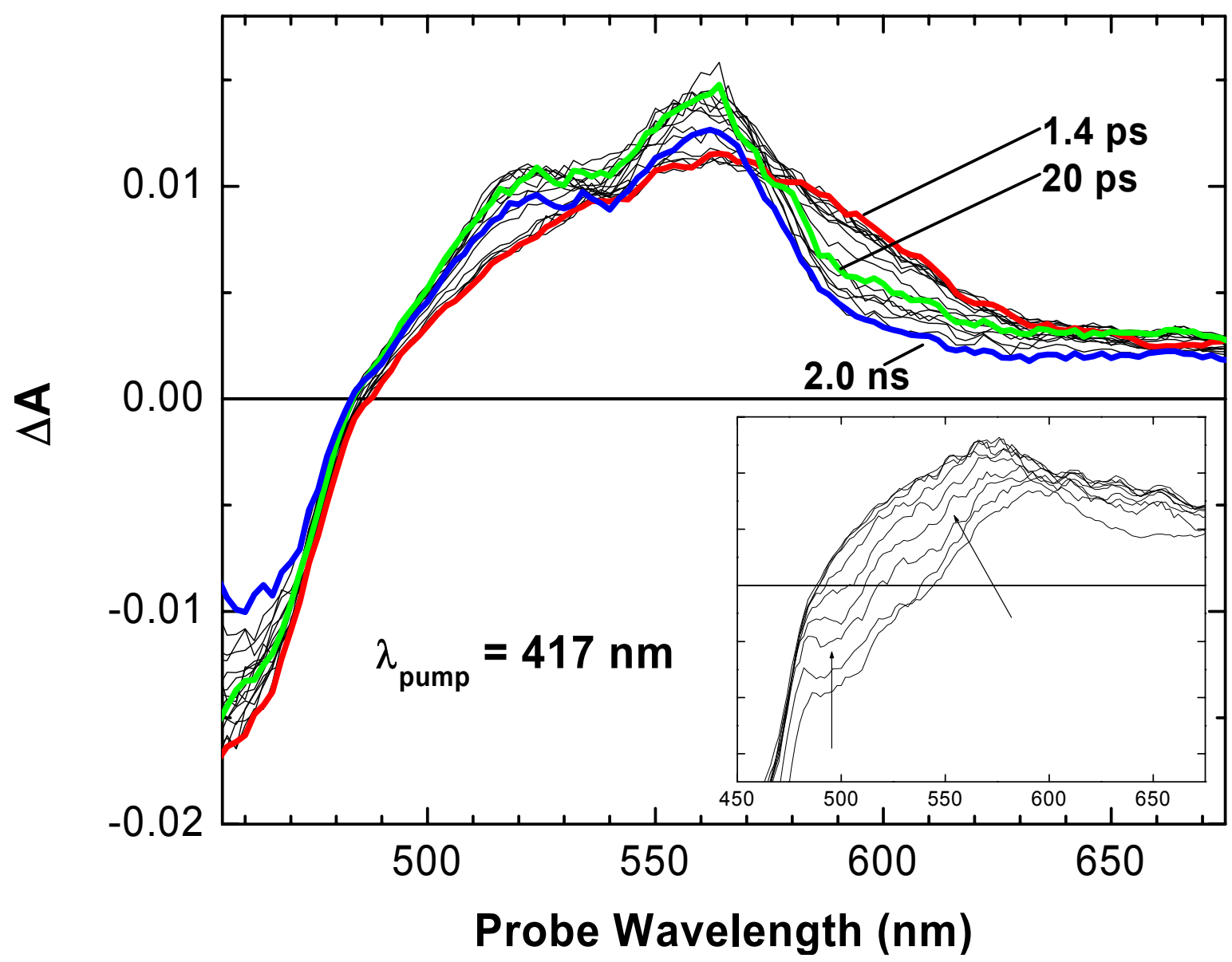

Figure 4. Transient spectra of $\left[\mathrm{Cu}(\mathrm{dmp})_{2}\right]^{+}$in toluene from 1.4 ps to $2.0 \mathrm{~ns}$. The inset shows earlier spectra from 0.3 to $1.2 \mathrm{ps}$. The right hand arrow on the inset spectra indicates that the initial growth for the transient absorption peak is shifting to the blue as it grows during the first few hundred femtoseconds. This was not observed in the acetonitrile results. 


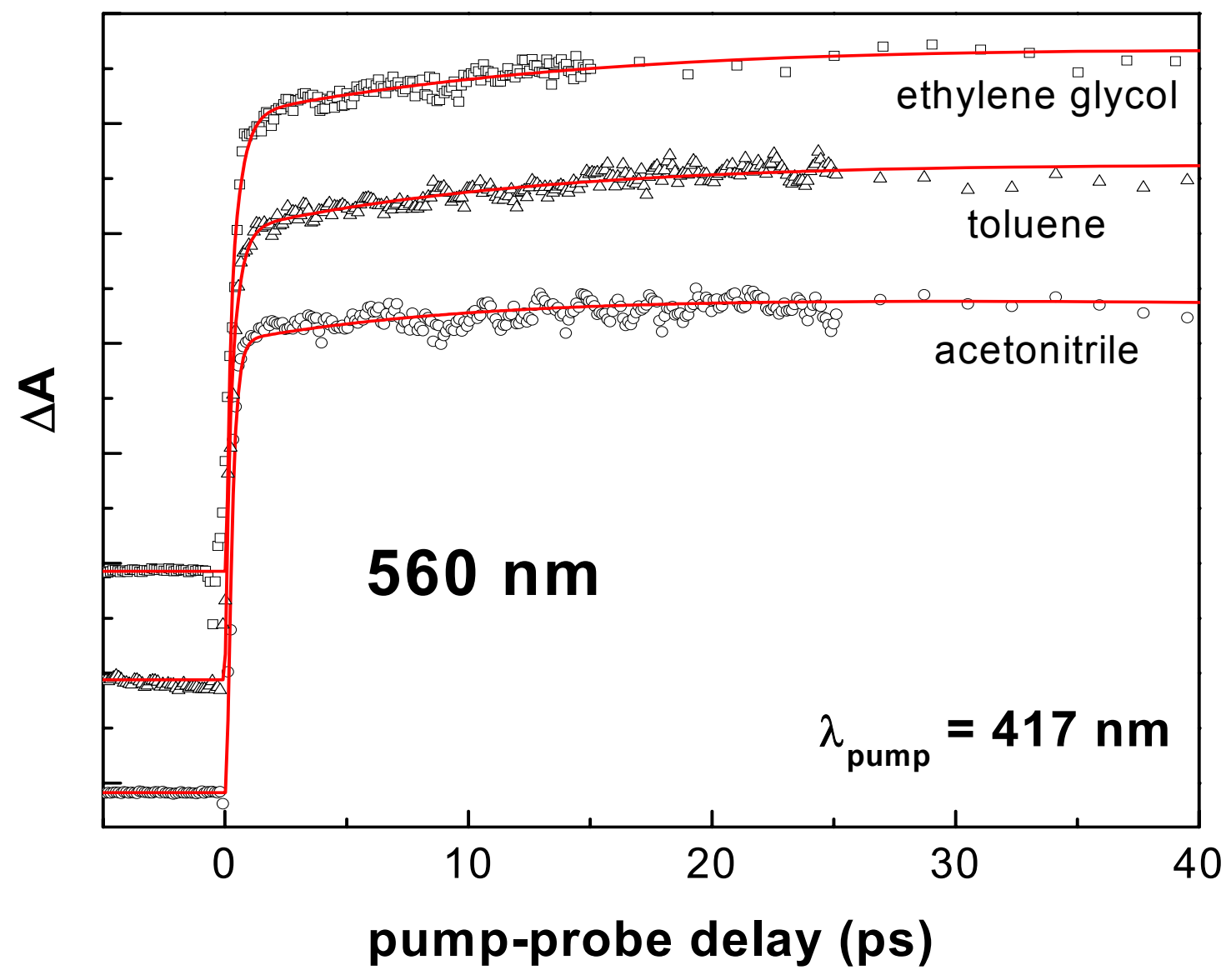

Figure 5. Transient signals observed as a function of pump-probe delay time at $560 \mathrm{~nm}$ for $\left[\mathrm{Cu}(\mathrm{dmp})_{2}\right]^{+}$ in the three solvents. (The transients are vertically offset for clarity.) This wavelength is the center of the more intense transient absorption peak that develops within 20 ps. Independent of the solvent, the fast and intermediate timescales (Tables 1-3) are $\sim 0.5$ and $10-15 \mathrm{ps,}$, respectively. While the origin of the sub-ps component is ambiguous, the slower rise time corresponds almost identically with the decay on the blue side of the absorption band. 


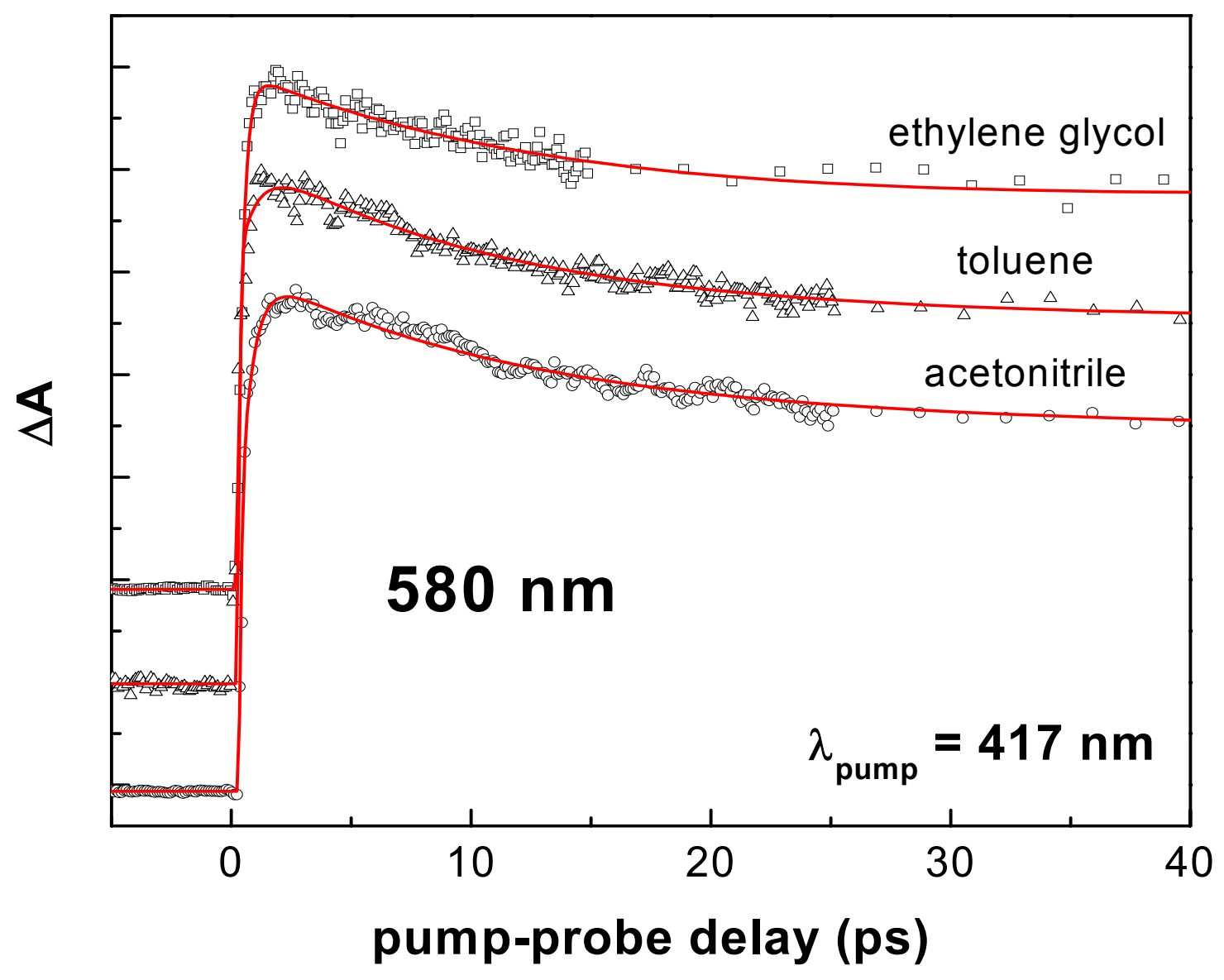

Figure 6. Transient signals observed as a function of pump-probe delay time at $580 \mathrm{~nm}$ for $\left[\mathrm{Cu}(\mathrm{dmp})_{2}\right]^{+}$ in the three solvents. (The transients are vertically offset for clarity.) This wavelength is on the blue side of the main transient absorption band which allows us to obtain the timescale of the blue shift and spectral reshaping that occurs within $20 \mathrm{ps}$. After a fast ( $\sim 0.5 \mathrm{ps})$ rise, the signal decays with a $10-15 \mathrm{ps}$ time constant (see Tables 1-3). 


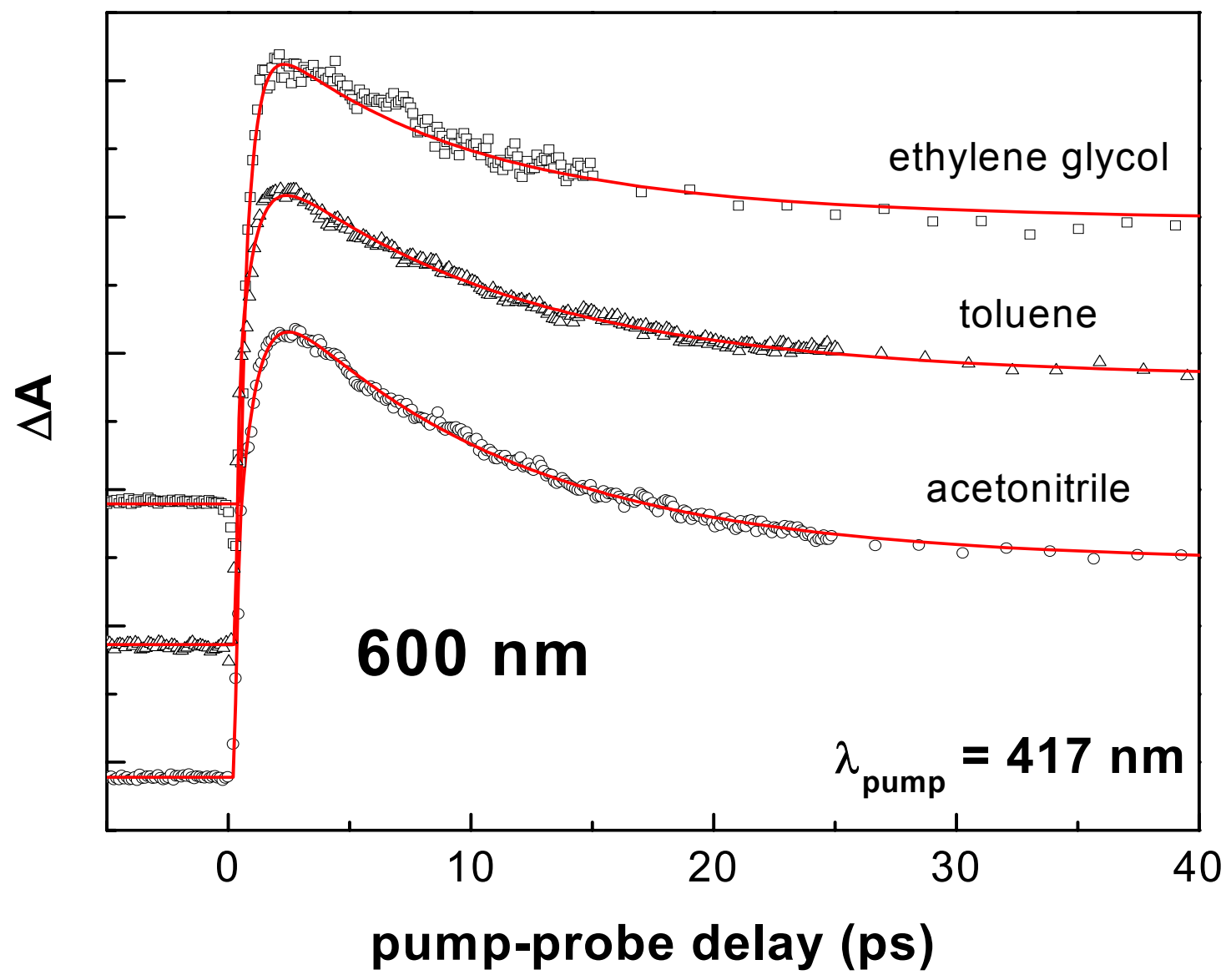

Figure 7. Transient signals observed as a function of pump-probe delay time at $600 \mathrm{~nm}$ for $\left[\mathrm{Cu}(\mathrm{dmp})_{2}\right]^{+}$ in the three solvents. (The transients are vertically offset for clarity.) At this wavelength, there is more spectral decay (than at $580 \mathrm{~nm}$ - Figure 6) resulting from the blue shift of the main transient absorption band. After a fast $(\sim 0.5 \mathrm{ps})$ rise, the signal decays with a $\sim 10 \mathrm{ps}$ time constant (see Tables $1-3$ ). Among the three transients presented above, the fit for the acetonitrile data has a larger amplitude for the 10 ps decay component than the other two, which explains its slightly different appearance. It is our view that the common timescale for the evolution in the various solvents (not the minor discrepancy in amplitudes) is relevant to assigning the dynamics. 


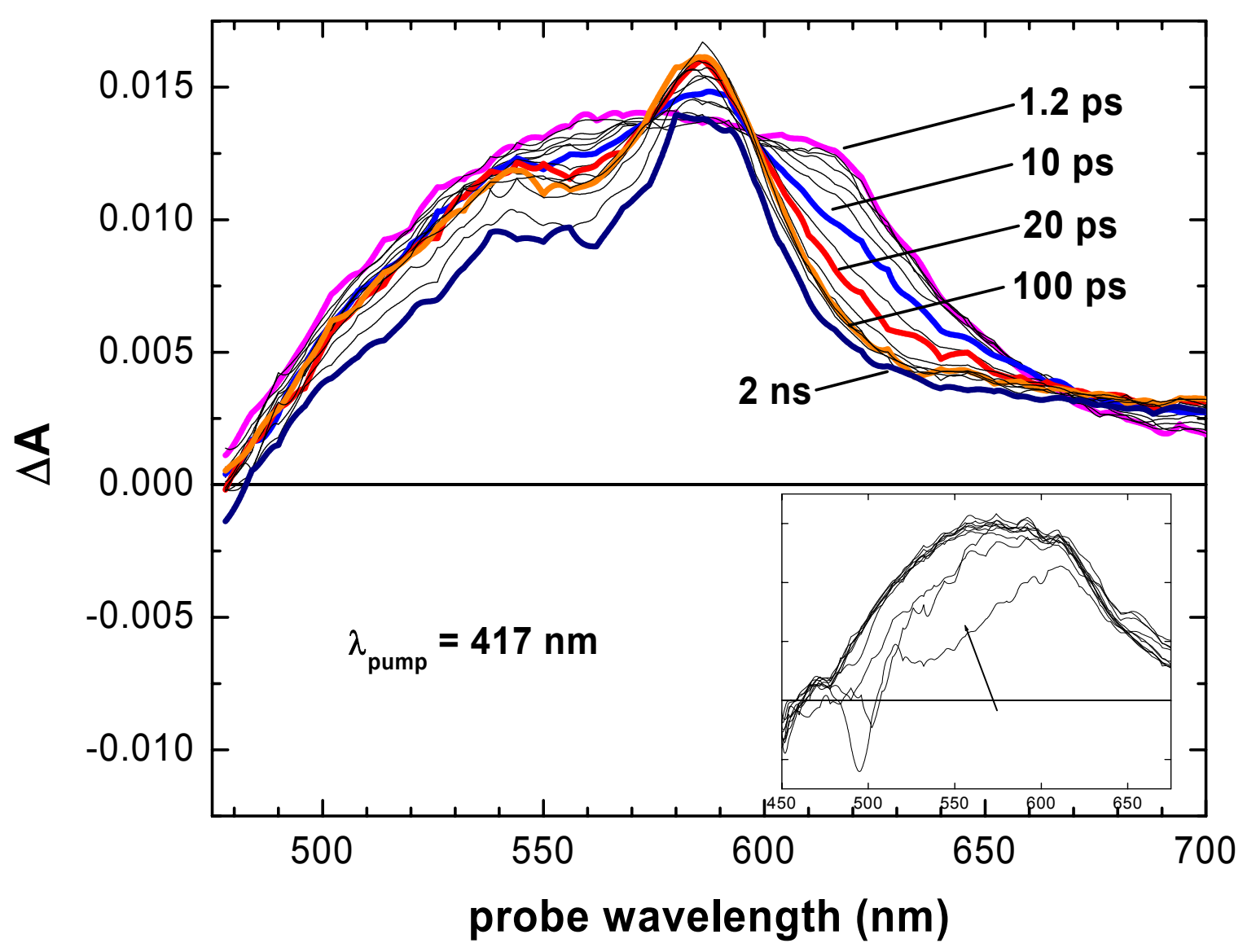

Figure 8. Transient spectra of $\left[\mathrm{Cu}(\mathrm{dpp})_{2}\right]^{+}$in acetonitrile from 1.2 ps to $2.0 \mathrm{~ns}$. The inset shows earlier spectra from 0.2 to $1.0 \mathrm{ps}$. The right hand arrow on the inset spectra indicates that the initial growth for the transient absorption is shifting to the blue as it grows during the first few hundred femtoseconds. 


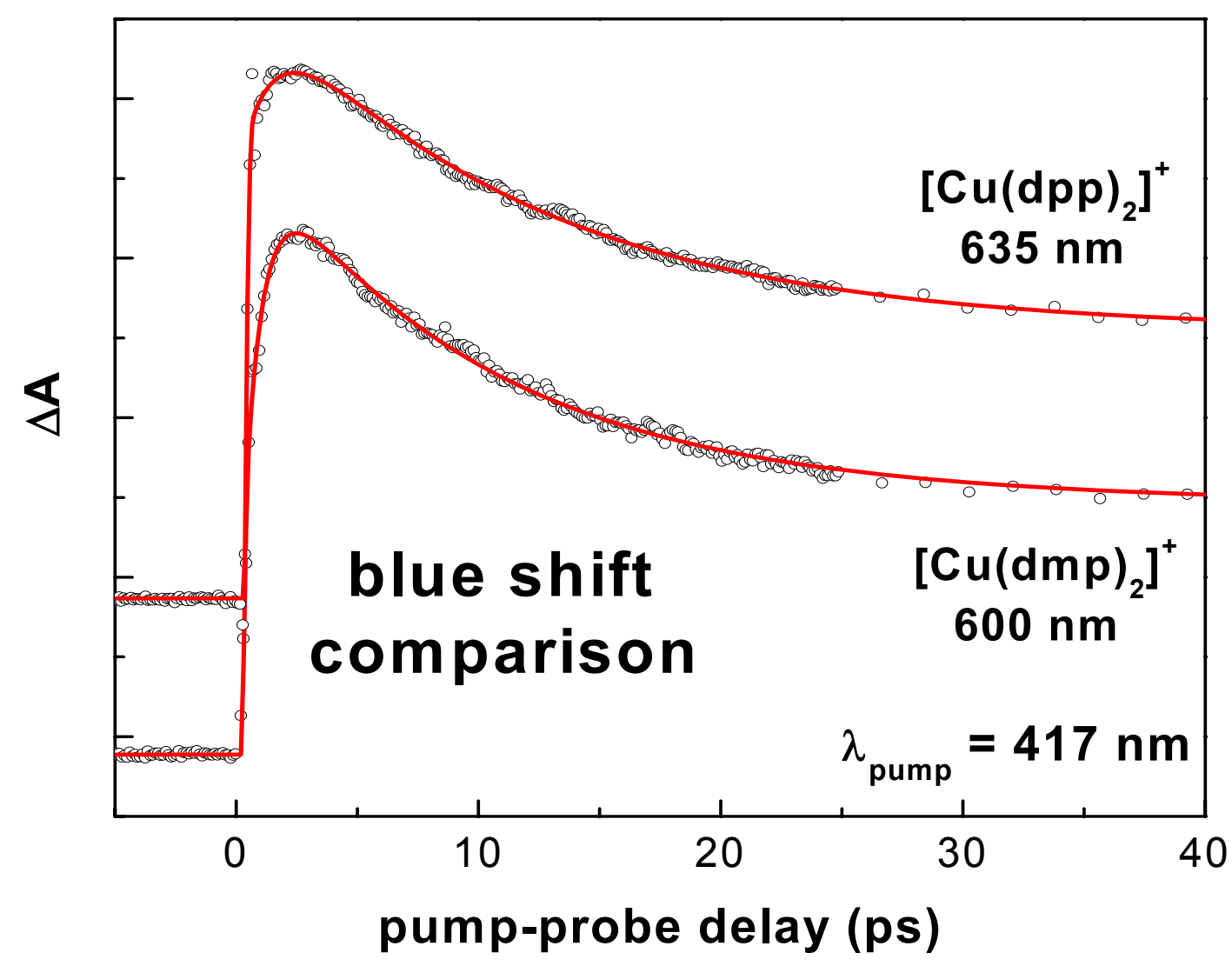

Figure 9. Comparison of the transient decays on the blue side of the excited-state absorption bands for $\left[\mathrm{Cu}(\mathrm{dmp})_{2}\right]^{+}$and $\left[\mathrm{Cu}(\mathrm{dpp})_{2}\right]^{+}$in acetonitrile. For the $\left[\mathrm{Cu}(\mathrm{dpp})_{2}\right]^{+}$data in this plot the time constants from fitting for this $635 \mathrm{~nm}$ transient are not listed in Table $4\left(\tau_{\mathrm{R} 1}=1.1 \mathrm{ps}\right.$ and $\left.\tau_{\mathrm{D} 1}=11 \mathrm{ps}\right)$. These probe wavelengths are chosen for display because they correspond to the middle of the blue side of the absorption for each molecule (to permit a more direct comparison). Although the initial rise of the $\left[\mathrm{Cu}(\mathrm{dpp})_{2}\right]^{+}$transient is slower than the $\left[\mathrm{Cu}(\mathrm{dmp})_{2}\right]^{+}$counterpart (1.1 ps vs. $0.78 \mathrm{ps}$, respectively), the timescale for the blue shift is virtually identical (11 ps vs. $10 \mathrm{ps}$, respectively). It is not surprising that the ultrafast scale of the initial rises would be slightly different, since the ligands are very different (electron-donating methyl groups in dmp versus phenyl groups in dpp). However, it is unexpected that the intermediate timescales would match up so well, given that the ligands are so dissimilar. Additionally, an $11 \mathrm{ps}$ blue shift is essentially the same as for $\left[\mathrm{Cu}(\mathrm{dmp})_{2}\right]^{+}$in ethylene glycol and toluene (see text). 


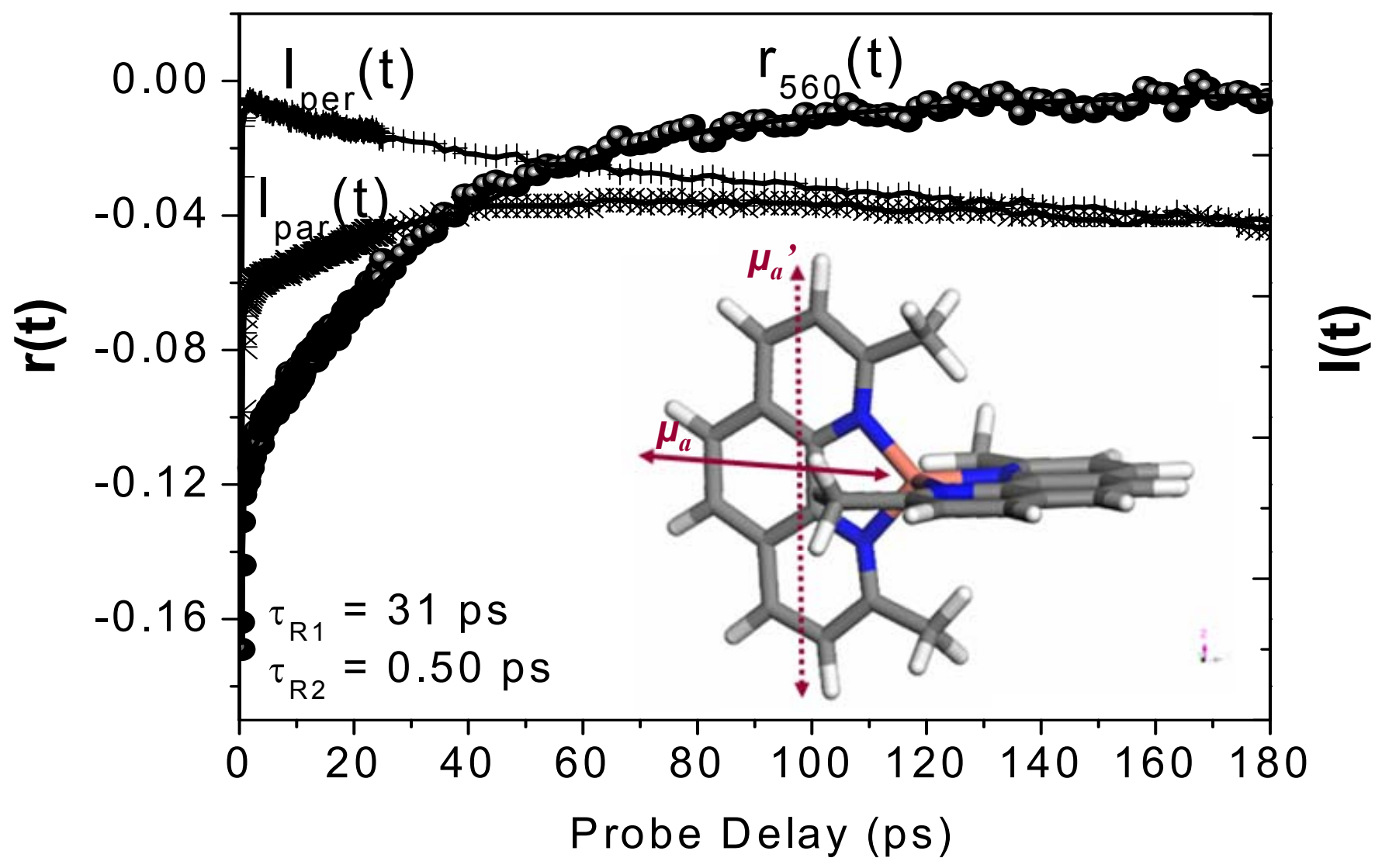

Figure 10. Transient excited state absorption anisotropy $\mathrm{r}(\mathrm{t})$ measured at $560 \mathrm{~nm}$. The left vertical axis is the anisotropy $\mathrm{r}(\mathrm{t})$ and the right axis is the absorption, or optical density change. The non-linear least square fit of $r(t)$ results in two decay time constants included in the figure. The arrows on the molecule indicate the transition dipole directions extracted from the data. $\mu_{a}$ and $\mu_{a}$ ' are transition dipole vectors corresponding to the transitions from $\mathrm{S}_{0} \rightarrow \mathrm{S}_{1}$ and $\mathrm{S}_{1}\left(\mathrm{~T}_{1}\right) \rightarrow \mathrm{S}_{\mathrm{n}}\left(\mathrm{T}_{\mathrm{n}}\right)$ respectively. 
A
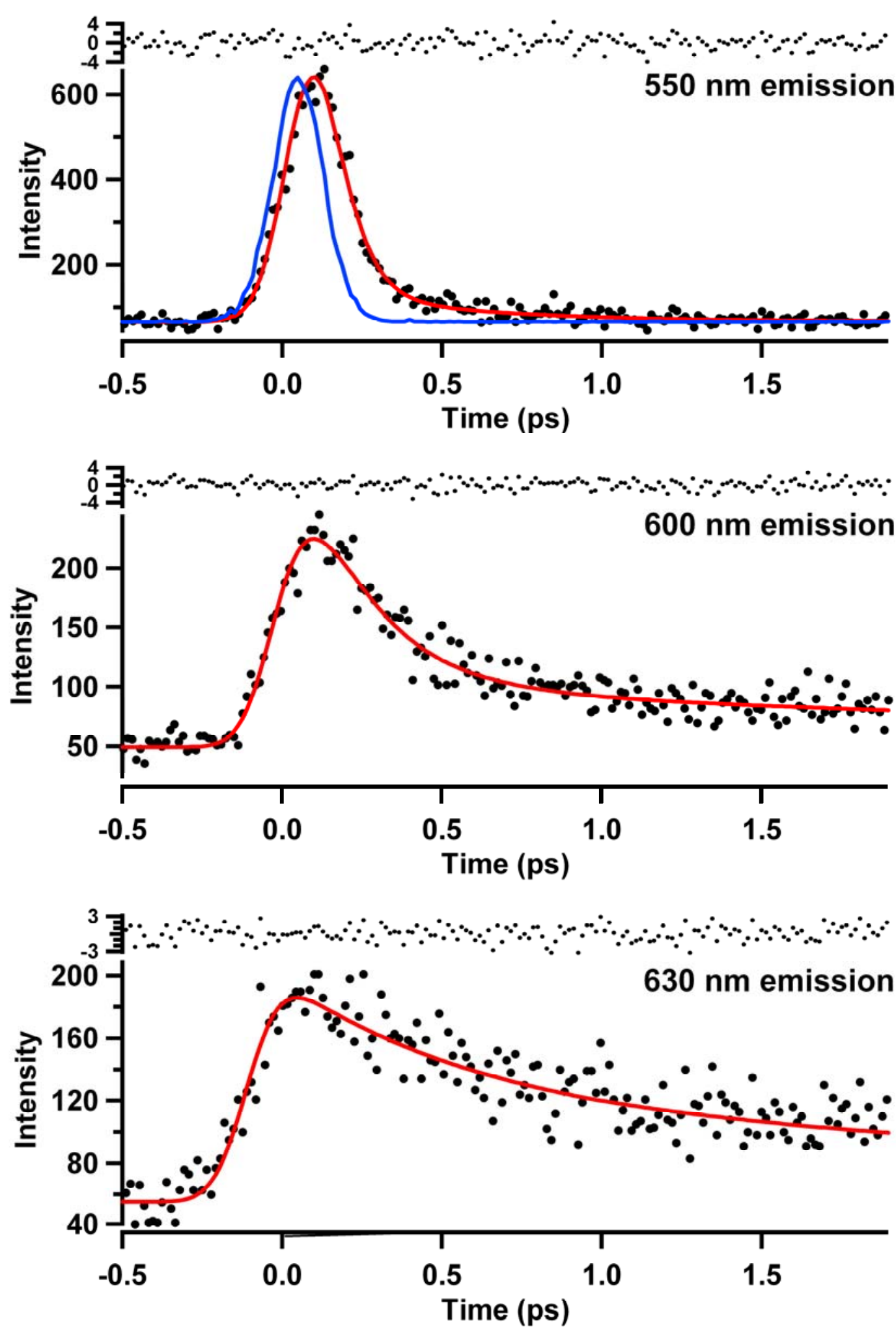

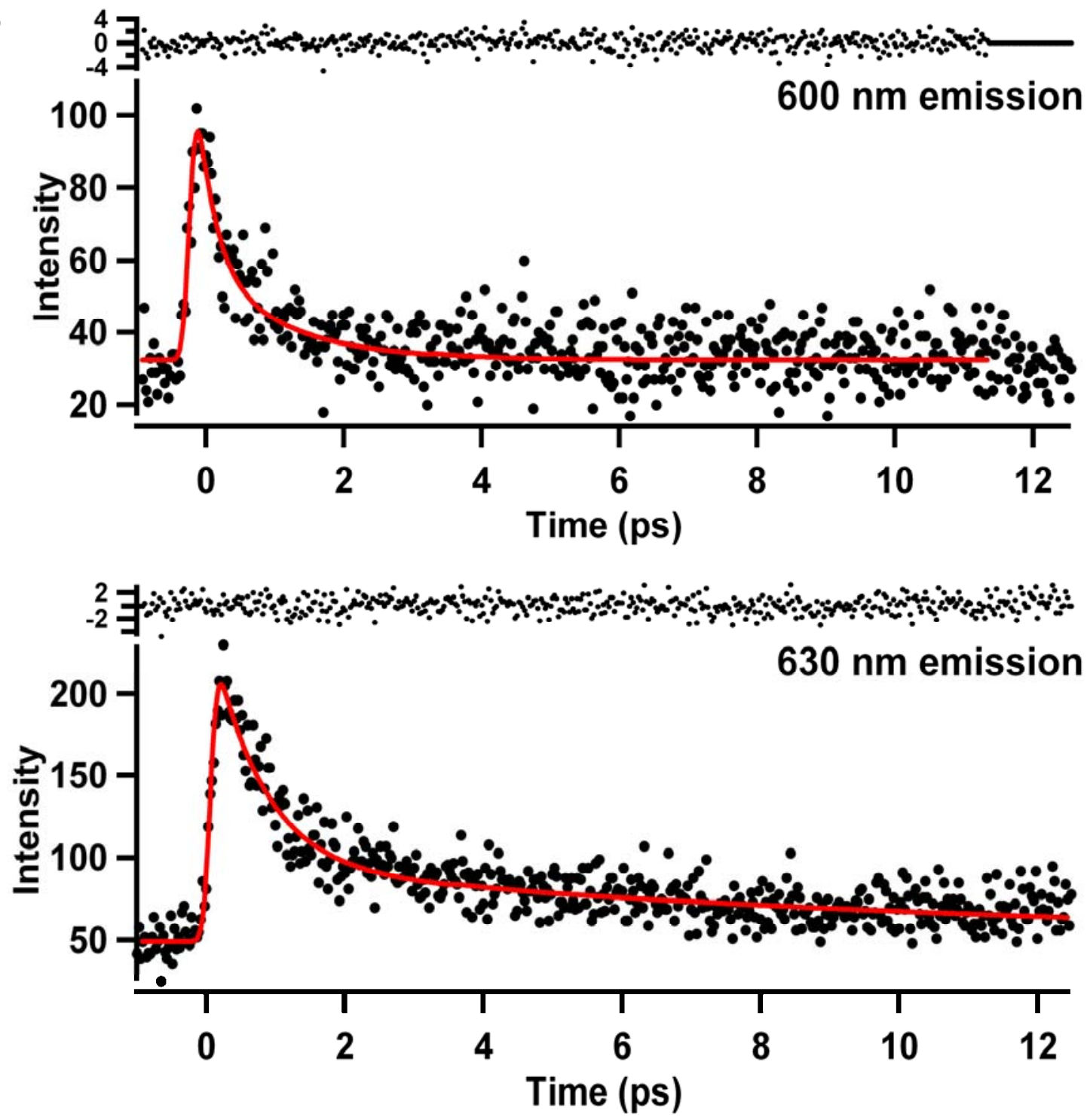

Figure 11. Fluorescence upconversion decay kinetics at different wavelengths with (A) a 2 ps time window, and (B) within a 12-ps time window showing variation of the rate constants with emission wavelength. The excitation wavelength for the fluorescence upconversion experiment was $418.5 \mathrm{~nm}$. Instrument response function is shown as a solid blue trace in (A) along with the $550 \mathrm{~nm}$ emission transient. 


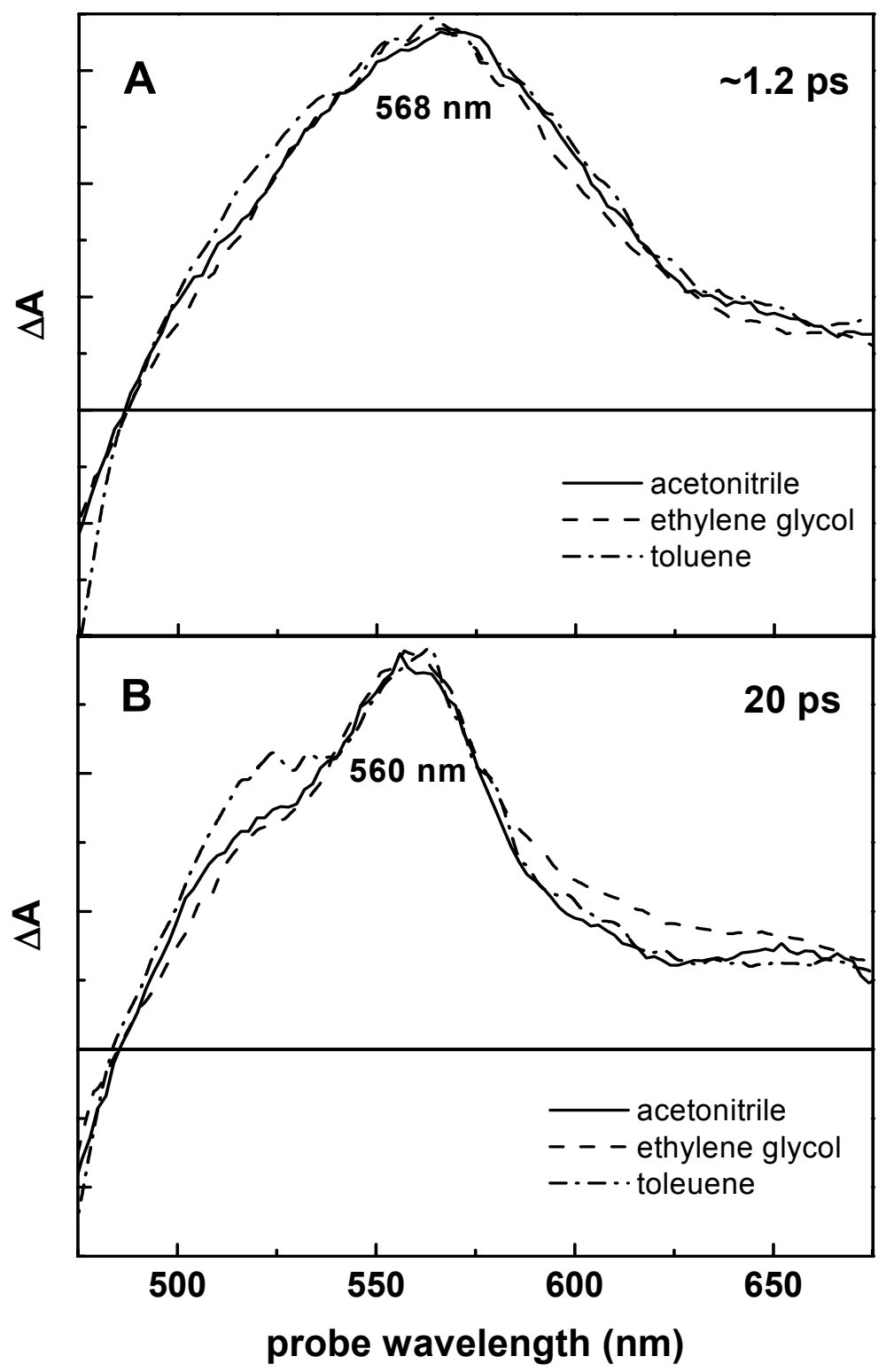

Figure 12. Normalized transient absorption spectra for $\left[\mathrm{Cu}(\mathrm{dmp})_{2}\right]^{+}$in acetonitrile $(-)$, ethylene glycol (- ) and toluene (-・-). A) Early time transient spectra showing a broad absorption band centered at approximately $568 \mathrm{~nm}$. This implies that the MLCT excited state at $\sim 1.2 \mathrm{ps}$ after photoexcitation is not affected by the solvent. B) Transient spectra at 20 ps show a narrowed, blueshifted dual peak structure with the more intense band centered at $560 \mathrm{~nm}$. The difference in peak positions between the $1.2 \mathrm{ps}$ spectra and the $20 \mathrm{ps}$ spectra corresponds to an energy difference of $0.057 \mathrm{eV}$ (see text for significance). It is clear that there are some differences between the $20 \mathrm{ps}$ spectra, with the toluene spectrum showing a more intense shoulder on the blue side of the main band and the ethylene glycol spectrum exhibiting a slightly more intense tail on the red side. But the basic shape and positions of the features are remarkably similar among the three solvents. It is not inherently obvious that these differences of intensity are necessarily significant. 


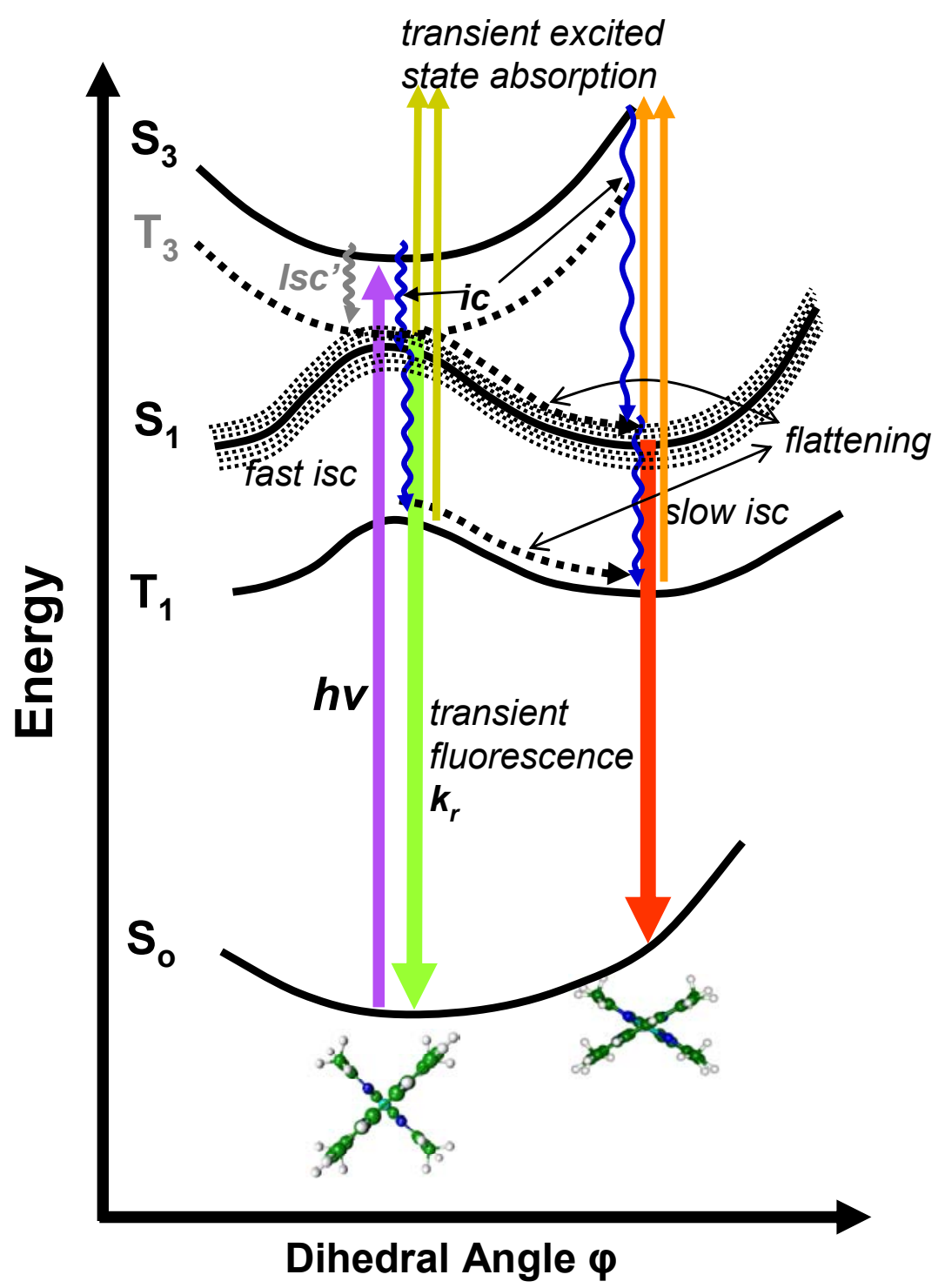

Figure 13. Illustration of potential energy surfaces for the excited and ground state $\left[\mathrm{Cu}(\mathrm{I})(\mathrm{dmp})_{2}\right]^{+}$with different transition processes indicated by arrows as labeled. The origin of the blue shits in the transient absorption due to both flattening and ISC is shown by the energy gaps associated with the two processes. The cluster of dashed potential surfaces for $S_{1}$ represents other degrees of freedom in molecular structure besides the dihedral angle, such as the solvent ligation, which will add additional dimensions of the complicated potential surface that is beyond the illustration. 


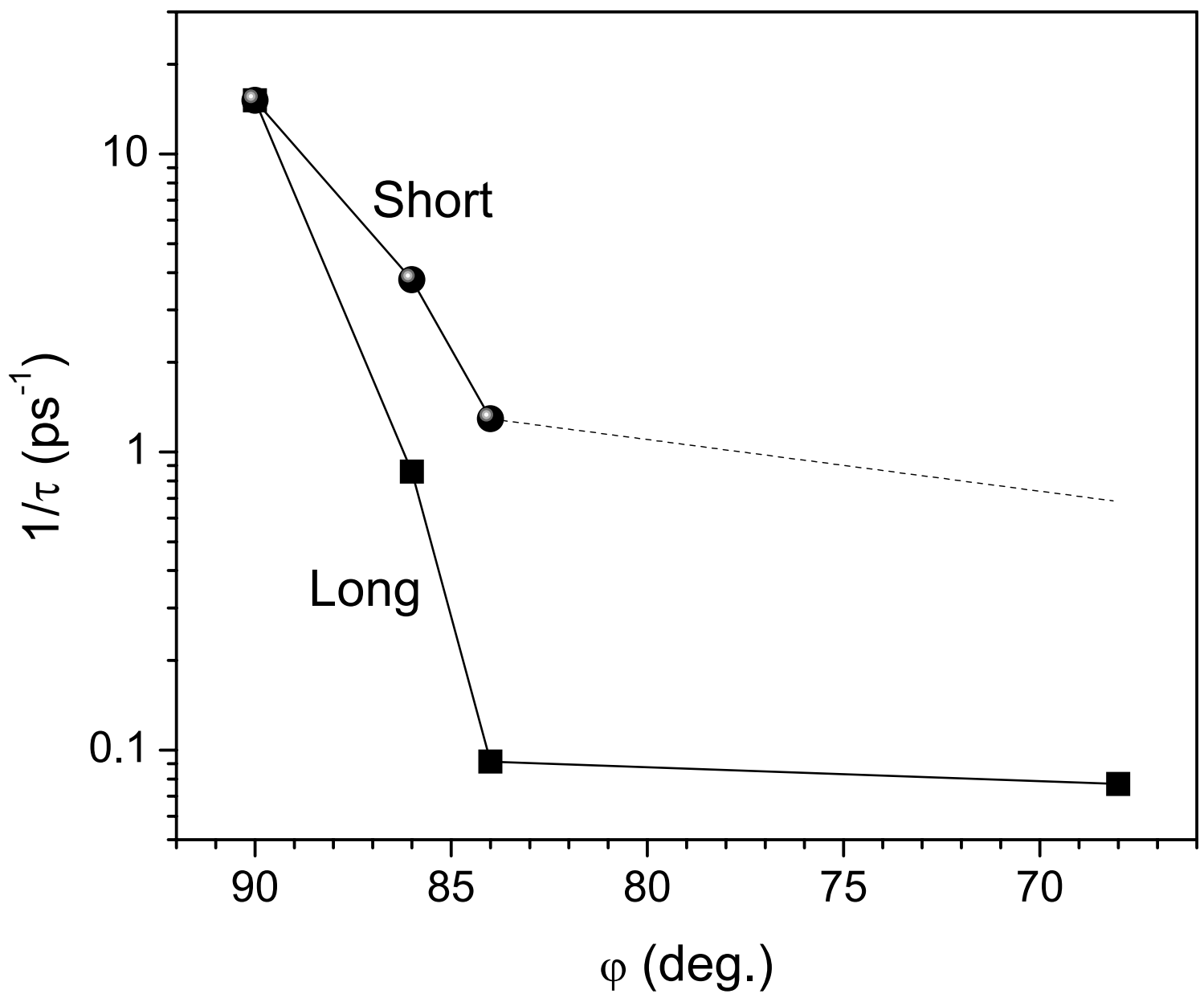

Figure 14. The plot from numerical values of $\tau$ vs. $\varphi$ generated by a harmonic oscillator model (see text) to express the biphasic nature of the dihedral angle dependence of the fluorescence lifetimes in the MLCT state of $\left[\mathrm{Cu}^{\mathrm{I}}(\mathrm{dmp})_{2}\right]^{+}$in acetonitrile solution. 


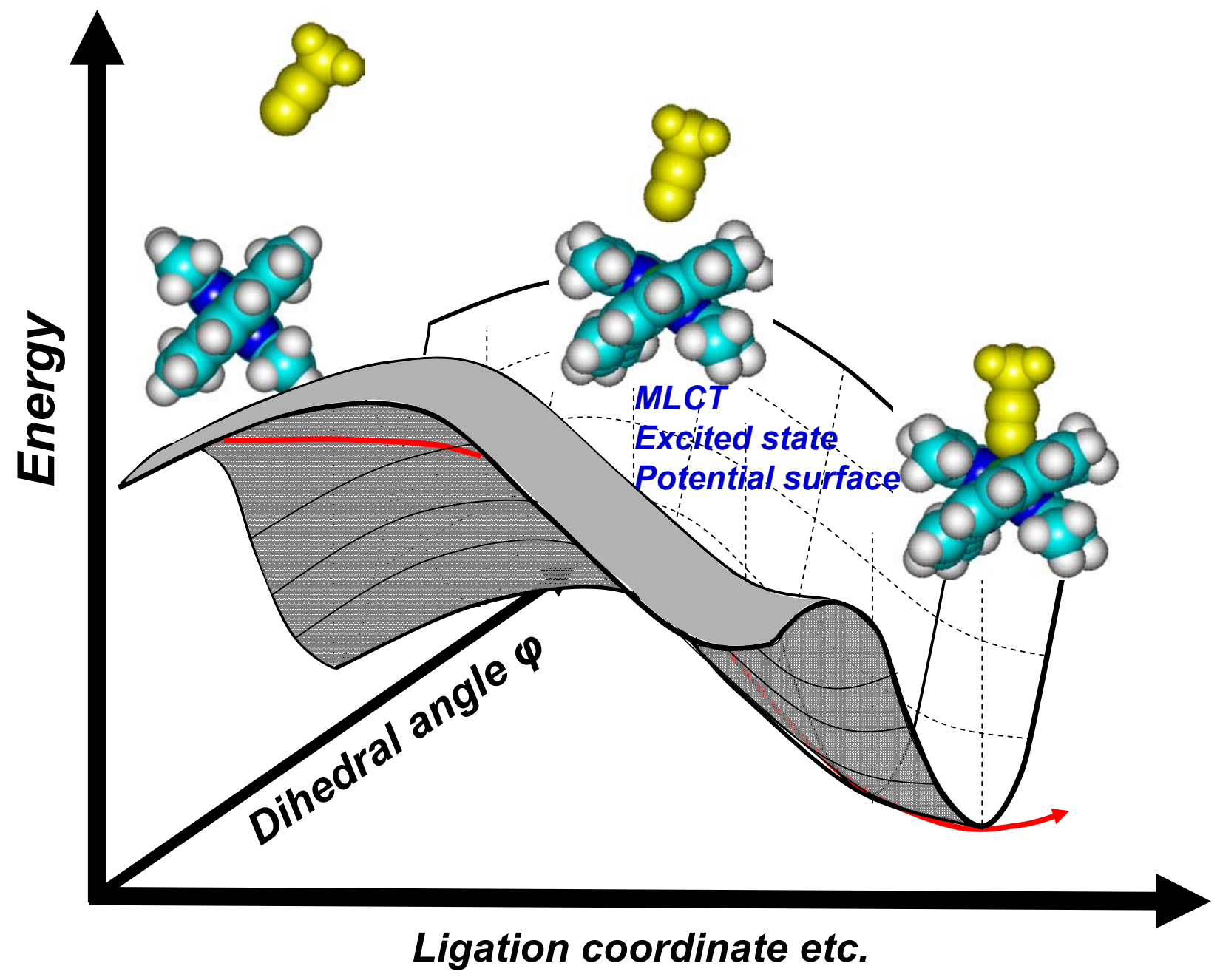

